\title{
International workshop on immune tolerance induction: consensus recommendations ${ }^{1}$
}

\author{
D. M. DIMICHELE, * W. K. HOOTS, $\dagger$ S. W. PIPE, $\$$ G. E. RIVARD $\mathbb{S}$ and E. SANTAGOSTINO \\ *Department of Pediatrics, Weill Medical College of Cornell University, New York, NY; †Department of Pediatrics, \\ University of Texas Medical School, Houston, TX; $\$$ Department of Pediatrics, University of Michigan, Ann Arbor, MI, \\ USA; \$Department of Pediatrics, University of Montreal, QC, Canada; and $\uparrow$ A. Bianchi Bonomi Hemophilia and \\ Thrombosis Center, IRCCS Maggiore Hospital, Mangiagalli and Regina Elena Foundation, University of Milan, Milan, \\ Italy
}

Summary. Although immune tolerance induction (ITI) has been used for 30 years to eliminate inhibitors and restore normal factor pharmacokinetics in patients with hemophilia, there is a paucity of scientific evidence to guide therapeutic decisionmaking. In an effort to provide direction for physicians and hemophilia treatment center staff members, an international panel of hemophilia opinion leaders met to develop consensus recom- mendations for ITI in patients with severe and mild hemophilia A and hemophilia B. These recommendations draw on the available published literature and the collective clinical experience of the group and are rated based on the level of supporting evidence .

Keywords: factor VIII, factor IX, hemophilia A, hemophilia $\mathrm{B}$, immune tolerance induction, inhibitors

\section{Introduction}

The development of inhibitors that neutralize the function of factor VIII (FVIII) or factor IX (FIX) is the most serious complication associated with the treatment of haemophilia. Inhibitors occur in up to $30 \%$ of patients with severe haemophilia A (FVIII $<1 \%$ of normal) [1-3], $0.9-7 \%$ of patients with mild to moderate haemophilia A [4] and 3\% of patients with haemophilia B [3]. The presence of an inhibitor does not increase mortality, but it complicates treatment and increases disease-related morbidity because bleeding episodes do not respond to standard therapy [5]. While large doses of factor can usually overcome low-titre inhibitors $(\leq 5$ Bethesda units (BU) [1]), high-titre inhibitors generally render factor replacement ineffective, and bypassing ther-

\footnotetext{
${ }^{1}$ This supplement was supported by an unrestricted grant from Baxter BioScience.

Donna M. DiMichele, MD, Department of Pediatrics, Cornell University, 525 E. 68th Street, Room P695, New York, NY 10021, USA.

Tel.: +1 212746 3418; fax: +1 212746 8986;

e-mail: dmdimich@med.cornell.edu

Accepted after revision 21 April 2007
}

apy is required [6]. Two bypassing agents are currently available: the activated prothrombin complex concentrate (aPCC), FEIBA ${ }^{\circledR}$ (Baxter AG, Vienna, Austria), and recombinant-activated FVII (rFVIIa; NovoSeven ${ }^{\circledR}$, Novo Nordisk, Bagsvaerd, Denmark). Both products have been shown to control at least $80 \%$ of bleeding episodes associated with high-titre inhibitors, including perioperative bleeding [7-13]. However, their haemostatic efficacy is difficult to predict $[6,14]$ and does not reach the overall success rates obtained with specific factor replacement in patients without inhibitors $[6,15]$. Furthermore, no laboratory assays are available that correlate with dosing or efficacy or predict complications [6]. Consequently, inhibitor patients, particularly those with high-titre, high-responding inhibitors, are at increased risk for uncontrollable haemorrhage, devastating joint disease and subsequent disability [16].

To reduce these risks and improve quality of life, immune tolerance induction (ITI) is usually attempted to eliminate high-responding (anamnestic) FVIII inhibitors of recent onset and restore normal factor pharmacokinetics [14]. ITI may also be performed, albeit far less frequently, in patients with high-titre FIX inhibitors. The Bonn protocol, first described in 1977 [17], is the prototype from which subsequent 
ITI regimens evolved. All regimens utilize ongoing, frequent, uninterrupted exposure to FVIII or FIX over a period of a few months to two or more years [18] with the goal of inducing antigen-specific tolerance $[14,19]$. Despite three decades of clinical experience with this modality, there is a lack of scientific evidence to direct ITI decision-making. Supporting data primarily come from small institutional studies and the three major ITI registries (International [20], German [21] and North American [22]). With regard to registry data, it was retrospectively collected several years ago, and the registries differed in terms of demographics; collection methods; and, in some instances, endpoints. The International Immune Tolerance Induction (I-ITI) Study [23], the first prospective, randomized, controlled trial of immune tolerance, was launched in July 2002 and currently involves 96 centres in 25 countries. This study is expected to resolve some of these unanswered questions, but the final results may not be known for several years, as subject accrual is ongoing.

To provide haemophilia caregivers with interim guidance, an international panel of haemophilia opinion leaders gathered in New York, NY, on 911 June 2006, and again in London, England, on 14 16 September 2006, to accomplish two goals: First, to critically evaluate the quality of the published literature on the clinical use of ITI, associated outcomes, and outcome-predictive variables in patients with inhibitors to FVIII or FIX. Secondly, to formulate consensus on a set of recommendations for ITI that draw on both the available published literature and the collective clinical experience of the group. These recommendations have been developed into decision-tree algorithms that physicians and haemophilia treatment centre (HTC) staff members may utilize and individualize according to the unique needs of each patient. The background,

Table 1. Levels of evidence [24].

\begin{tabular}{ll}
\hline Level & Evidence \\
\hline Ia & Meta-analysis of randomized controlled trials (RCT) \\
Ib & At least one RCT \\
IIa & At least one well-designed, controlled study without \\
& randomization \\
IIb & At least one other type of well-designed, \\
& quasi-experimental study \\
III & Well-designed, non-experimental, descriptive studies \\
& (e.g. comparative studies, correlational studies, \\
& and case-control studies) \\
IV & Expert committee reports or opinions and/or clinical \\
& evidence offered by respected authorities \\
\hline
\end{tabular}

Haemophilia (2007), 13 (Suppl. 1), 1-22 rationale and support for the algorithms are described in detail. Each practice recommendation has been assigned a rating based on the level of available supporting evidence (Table 1) [24]. In addition to these algorithms, the panel developed a list of research priorities. This investigational call-to-action is presented at the end of the supplement.

We are grateful for the opportunity to be guest editors of this supplement to Haemophilia and to work with our colleagues from Europe and North America to develop the recommendations for ITI. The names and affiliations of the co-authors in alphabetical order are:

\section{Charles Hay}

Manchester Royal Infirmary

Manchester, UK

Thierry Lambert

Hôpital Bicêtre

Le Kremlin Bicêtre, France

Cindy Leissinger

Tulane University School of Medicine

New Orleans, LA, USA

David Lillicrap

Queen's University

Kingston, ON, Canada

Johannes Oldenburg

University Clinic Bonn

Bonn, Germany

Kathelijne Peerlinck

KU Leuven Universitaire Ziekenhuizen

Leuven, Belgium

Pia Petrini

Karolinska University Hospital

Stockholm, Sweden

Michael Recht

Phoenix Children's Hospital

Phoenix, AZ, USA

Mark Reding

University of Minnesota

Minneapolis, MN, USA

Chantal Rothschild

Centre d'Hémophilie F. Josso

Paris, France 


\section{Immune tolerance induction in patients with severe haemophilia A}

\section{Overview of inbibitor formation}

Studies in previously untreated patients (PUPs) with severe haemophilia A suggest that most FVIII inhibitors develop early in life (median age, 1.7-3.3 years), with the highest risk during the first 50 exposure days to factor concentrate $[25,26]$. Although genetic markers indicating a predisposition to inhibitor development are not fully identified, several other host factors are known to influence the risk of inhibitor development. In addition to the type and severity of haemophilia, these include FVIII gene mutations, primarily large defects in multiple domains [27]; polymorphisms in genes involved in the regulation of the immune system [28-30], which suggest that inhibitor formation is a polygenic process; family history, linked to approximately a threefold increased risk of inhibitor development [31]; and African heritage, which doubles the risk [32]. In addition, differences in the major histocompatibility complex, a critical component of the immune system, may contribute to inhibitor development [33]. The likelihood of inhibitor formation may also be increased by environmental factors, such as age at first factor exposure [34], intensive FVIII exposure during infancy [35], immunologic challenge (e.g. infection, surgery, immunization) [36], or choice of FVIII replacement concentrate (i.e. recombinant or plasma-derived) [37], but their roles in the aetiologic process remain less certain. The entire ITI algorithm for patients with severe haemophilia A is presented in Fig. 1. The following sections discuss the various components of this algorithm.

\section{When to Start ITI}

In 1999, Kroner [38] published a meta-analysis of the data from the International Immune Tolerance Registry (IITR) and the North American Immune Tolerance Registry (NAITR). Collectively, these data included information on 437 patients with haemophilia A and B evaluated for ITI. Among the putative predictors of ITI success, only two were found to be statistically significant in this meta-analysis: historical peak inhibitor titre and titre at the initiation of ITI. ITI was successful in $82 \%$ of patients whose peak titres were $<50 \mathrm{BU}$, and as the historical titre increased, success rates diminished (Table 2). This inverse correlation between historical peak titre and successful tolerance was also observed in the German ITI registry [21].
Table 2. IITR and NAITR data meta-analysis: outcome by maximum historical titre [38].

\begin{tabular}{lllllr}
\hline & \multicolumn{4}{l}{ Maximum historical titre (BU) } & \\
\cline { 2 - 5 } & $<50$ & $50-200$ & $201-500$ & $>500$ & Total \\
\hline IITR $n(\%)$ & & & & & \\
$\quad$ Success & $64(82)$ & $24(65)$ & $9(56)$ & $17(50)$ & 114 \\
Failure & $14(18)$ & $13(35)$ & $7(44)$ & $17(50)$ & 51 \\
$\quad$ Total $(P=0.004)$ & 78 & 37 & 16 & 34 & 165 \\
NAITR $n(\%)$ & & & & & \\
$\quad$ Success & $71(82)$ & $18(69)$ & $4(40)$ & $1(7)$ & 94 \\
Failure & $16(18)$ & $8(31)$ & $6(60)$ & $13(93)$ & 43 \\
$\quad$ Total $(P=0.001)$ & 87 & 26 & 10 & 14 & 137 \\
\hline
\end{tabular}

Reprinted with permission (pending) from Kroner BL. Comparison of the international immune tolerance registry and the North American immune tolerance registry. Vox Sang. 1999; 77(Suppl. 1):33-37.

IITR, International Immune Tolerance Registry; NAITR, North American Immune Tolerance Registry.

While the maximum historical inhibitor titre may influence decisions about whether to attempt ITI, the pre-ITI titre is relevant to decisions about when to start immune tolerance. An inhibitor titre of $<10 \mathrm{BU}$ immediately before ITI initiation positively affected both the likelihood of success and the time required to achieve tolerance in the IITR and NAITR (Table 3) [22], the German registry [21], the Spanish registry [39] and in several institutional studies [40-44]. There is some suggestion that waiting until the inhibitor titre falls below 5 BU may further improve response [22], but this has yet to be firmly established. Thus, reasonable evidence supports the recommendation that ITI should generally be deferred until the inhibitor titre has dropped below $10 \mathrm{BU}$, although this may not be the absolute cutoff. This postponement typically delays the start of ITI by 3-6 months. According to an early progress report from the I-ITI study, the median delay between inhibitor development and a drop in the inhibitor titre below $10 \mathrm{BU}$ has been 6 months [23]. Despite waiting for the inhibitor titre to fall, the median age of the children at the start of ITI was only 25 months. Close surveillance of inhibitory antibody levels during the waiting period is essential to ensure the prompt initiation of immune tolerance once the titre falls sufficiently or alternative action if it does not. During this interval, exposure to FVIII should be avoided or minimized by discontinuing FVIII prophylaxis (if applicable) and treating intercurrent bleeding on-demand with bypassing therapy [18]. rFVIIa is the preferred agent for acute haemorrhage management in this setting [18] since FEIBA, which contains residual FVIII antigen, may cause anamnesis [26].

When bleeding is life- or limb-threatening or has the potential to cause significant morbidity 
4 D. M. DIMICHELE et al.

\begin{tabular}{|l|l|}
\hline Wait until INH titer $<10 \mathrm{BU}$ (level IIb) \\
- Wait is usually fairly short \\
- Most children will still be very young at start of ITI \\
- Close surveillance of INH titer during waiting period is essential \\
- Avoid FVVII exposure during waiting period \\
$-10 \mathrm{BU}$ may not be absolute cut-off
\end{tabular}

- ITI successful using FVIII products with and without VWF (level IIb)

- No definitive data support superiority of any FVIII product (level IIb)

- Most patients are tolerized with same product in use at time of INH detection (level Ilb)

- This approach works

- No evidence to support switching to another FVIII product for de novo ITI

Immunoadsorption (IA)

- No role for IA as a first-line ITI component (level Illb)

\section{Prophylaxis During ITI}

• rFVIII $\left(90-270 \mathrm{\mu g} \mathrm{kg}^{-1} \mathrm{day}^{-1}\right) \stackrel{\text { Pre-ITI (level IV) }}{ }$

$\downarrow$

*Very good-risk patient: peak historical titer $<50 \mathrm{BU}$.

${ }^{\dagger}$ Higher doses used for ICH.

\begin{tabular}{|c|}
\hline $\begin{array}{l}\text { During ITI } \\
\text { - Early joint bleeding or ICH (level III) } \\
\text { - FEIBA ( } 50-200 \mathrm{U} \mathrm{kg}^{-1} \mathrm{QD} \text { toBIW) } \\
\text { - IFVIIIa ( } 90-270 \mathrm{\mu g} \mathrm{kg}^{-1} \text { day) } \\
\text { - Monitor FVIII recovery when INH titer }=10 \mathrm{BU} \text { (level IV) } \\
\text { - DC bypassing therapy at any level of FVIII recovery (level IV) }\end{array}$ \\
\hline
\end{tabular}

Recommendations (level IV)
- Use peripheral venous access whenever possible
- Ports are preferable to external catheters
- Follow published guidelines for catheter care
- Instruct families on CVAD techniques before starting ITI
- AVF is a protocol-driven option for venous access in children $\geq 1$ year who have
experienced repeated CVAD failure
- Surgical expertise essential
- Long-term follow-up with ultrasonography and
echocardiography required
- Dismantle AVF as soon as peripheral veins provide adequate access

\section{CVAD Issues}

$1 \quad 1$

Complications (level IV)
-CVAD-related infection
- Follow published consensus guidelines for infection management
- CVAD-related thrombosis
- Stop bypassing prophylaxis
- Review infusion technique with family
- Consider
- Removing catheter
- Modifying ITI regimen
- Close observation for clot resolution
- If clot is severe/progressive, consider
- Catheter-directed thrombolysis
- Anticoagulation (short course)
- AVF-related thrombosis
- Stop bypassing prophylaxis
- Continue ITI

Fig. 1. Severe haemophilia A: recommended ITI algorithm. 


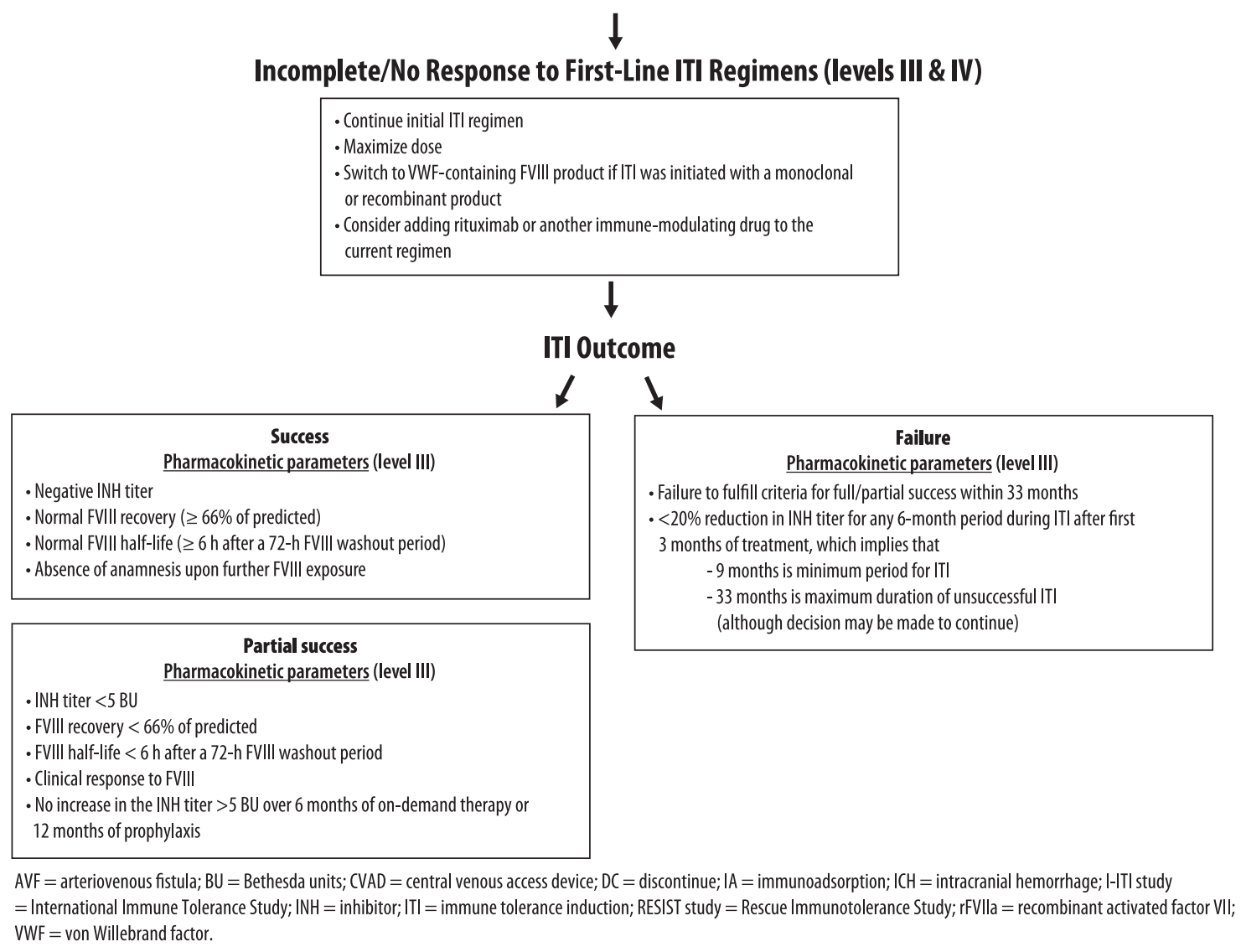

Fig. 1. Continued.

Table 3. IITR and NAITR data meta-analysis: outcome by Pre-ITI titre [38].

\begin{tabular}{|c|c|c|c|c|c|}
\hline & \multicolumn{4}{|c|}{ Pre-ITI titre (BU) } & \multirow[b]{2}{*}{ Total } \\
\hline & $<10$ & $10-20$ & $21-50$ & $>50$ & \\
\hline \multicolumn{6}{|l|}{ IITR $n(\%)$} \\
\hline Success & $65(79)$ & $16(76)$ & $5(36)$ & $15(53)$ & 101 \\
\hline Failure & $17(21)$ & $5(24)$ & $9(64)$ & $13(46)$ & 44 \\
\hline Total $(P=0.002)$ & 82 & 21 & 14 & 28 & 145 \\
\hline \multicolumn{6}{|l|}{ NAITR $n(\%)$} \\
\hline Success & 73 (87) & $9(50)$ & $5(38)$ & $6(33)$ & 93 \\
\hline Failure & $11(13)$ & $9(50)$ & $8(62)$ & $12(67)$ & 40 \\
\hline Total $(P=0.001)$ & 84 & 18 & 13 & 18 & 133 \\
\hline \multicolumn{6}{|c|}{$\begin{array}{l}\text { IITR, International Immune Tolerance Registry; NAITR, North } \\
\text { American Immune Tolerance Registry. } \\
\text { (e.g. haemarthrosis with risk of target joint develop- } \\
\text { ment), it may be prudent to start ITI prior to the } \\
\text { desired decline in titre to < } 10 \text { BU. A significant } \\
\text { association between outcome and time from inhibitor } \\
\text { diagnosis to ITI was observed in the IITR, although } \\
\text { this association was only of borderline significance in } \\
\text { the NAITR [38]. Nonetheless, success rates for both } \\
\text { registries were at their lowest after } 5 \text { years ( } 51 \% \text { for } \\
\text { the IITR, } 57 \% \text { for the NAITR). Consequently, if the }\end{array}$} \\
\hline
\end{tabular}

waiting period for the inhibitor to decline extends beyond 1-2 years, the advantages and disadvantages of beginning ITI at a titre higher than $10 \mathrm{BU}$ should be considered.

Consensus recommendations for when to start ITI (Fig. 1)

1 Postpone the initiation of ITI until the inhibitor titre has dropped to $<10 \mathrm{BU}$, although an even lower inhibitor titre may be more beneficial (level IIb).

a. The waiting time is usually short, and most children will still be very young at the start of ITI.

b. Closely monitor inhibitory antibody levels during the waiting period to ensure that ITI is started promptly once the titre falls sufficiently.

c. Avoid FVIII exposure during the waiting period.

2 Consider starting ITI regardless of the inhibitor titre if (level IV)

a. The inhibitor titre does not fall below $10 \mathrm{BU}$ within a 1-2 year period of close observation.

b. A severe life- or limb-threatening bleeding event occurs. 


\section{FVIII dose}

\section{Dosing regimens}

Three primary therapeutic regimens have been developed for inhibitor eradication (Table 4). The high-dose Bonn protocol currently calls for the administration of FVIII at a dosage of $150 \mathrm{IU} \mathrm{kg}^{-1}$ twice daily [41]. FEIBA ( $50 \mathrm{U} \mathrm{kg}^{-1}$ b.i.d.) is added in patients at high risk of bleeding and is continued until the inhibitor titre falls below $1 \mathrm{BU}$. The Bonn protocol is intensive for patients and families and very costly because of high-FVIII consumption.

Table 4. Primary therapeutic regimens used for ITI.

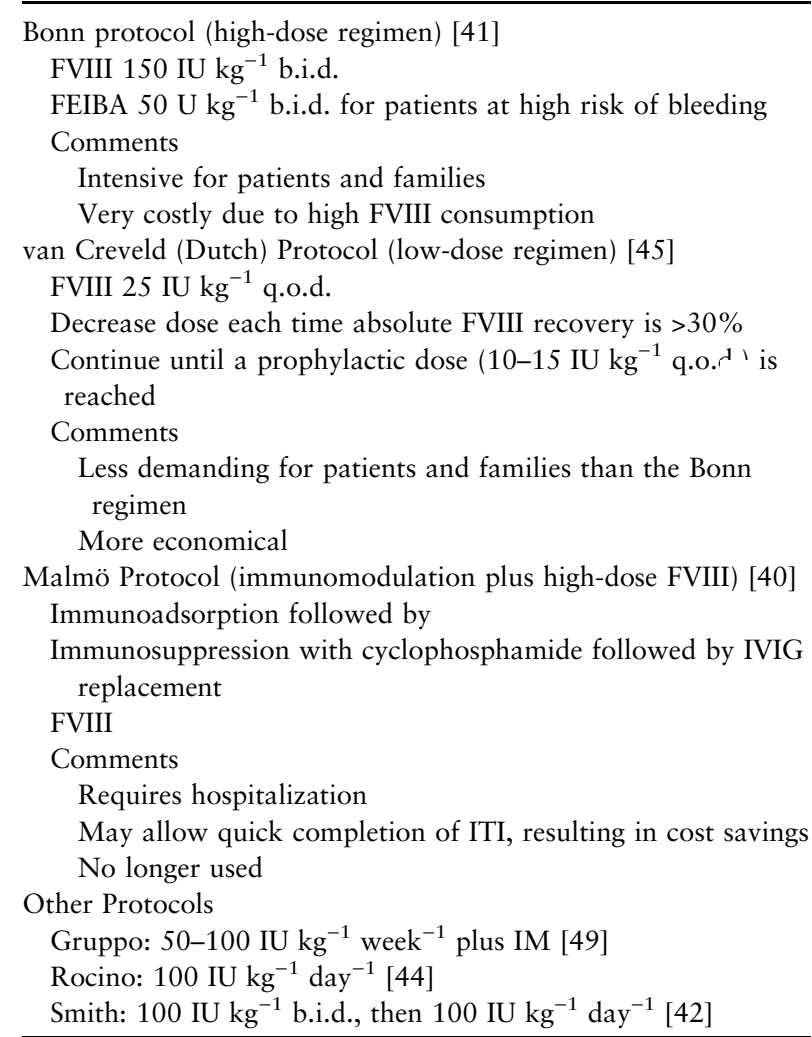

b.i.d., twice daily; IVIG, intravenous immune globulin; IM, immunomodulation; q.o.d., every other day.

In the low-dose van Creveld (Dutch) regimen, FVIII is administered every other day at a dose of $25 \mathrm{IU} \mathrm{kg}^{-1}$ [45]. The dose is decreased each time the absolute FVIII recovery exceeds $30 \%$. These reductions are continued until a prophylactic FVIII dose of $10-15 \mathrm{IU} \mathrm{kg}^{-1}$ three times weekly is reached.

The Malmö protocol utilizes extracorporeal immunoadsorption with protein A columns as needed to remove high-titre inhibitory antibodies $(>10 \mathrm{BU})[40,46]$. This process is followed by immunomodulation using intravenous and oral cyclophosphamide and intravenous immune globulin (IVIG) combined with high-dose FVIII (Bonn regimen). Hospitalization is required, but tolerization has been reported in as little as 3-4 weeks. The Malmö protocol is no longer used in Sweden for ITI because the long-term follow-up showed that responses were not always durable [40,46,47], and that success rates were no higher than for regimens that do not use immunomodulation [40]. Furthermore, immunoadsorption may be difficult in small children [18], and the use of cyclophosphamide is potentially associated with an increased risk of myelosuppression, leukemia and sterility [48]. These side effects of cyclophosphamide are thought to be dose-related, however, and may not occur at the doses used in the Malmö protocol. In addition to these ITI regimens, various intermediate-dose protocols have been developed at and are used by individual HTCs worldwide $[42,44,49]$.

\section{Dosing considerations}

Controversy persists regarding the roles of FVIII dose and dosing regimen as predictors of ITI success [19]. While many investigators have reported similar rates of successful tolerization (63-91\%) despite the use of widely disparate therapeutic dosing regimens $[40,42,44,49-51]$, the registries generated varied data in this regard $[20,38,52-54]$. In the IITR, daily FVIII doses of at least $200 \mathrm{IU} \mathrm{kg}^{-1}$ resulted in a statistically significant improvement in outcome $(86 \% ; P=0.001)$ [55]. In contrast, the NAITR observed a significant inverse relationship between FVIII dose intensity and overall ITI success. Success rates were $80 \%$ for daily doses of $<50 \mathrm{IU} \mathrm{kg}^{-1}$, compared with $41 \%$ for doses of $200 \mathrm{IU} \mathrm{kg}^{-1}$ day $^{-1}$ or higher $(P=0.01)$ [54]. Tolerization was achieved more rapidly, however, when higher doses were used ( $\geq 50 \mathrm{IU} \mathrm{kg}^{-1} \mathrm{day}^{-1}$ ) [53,54].

A meta-analysis of the two registries found that FVIII dosing had no impact on ITI success rates for 'good-risk' patients with historical inhibitor titres below $200 \mathrm{BU}$ and pre-ITI titres of $<10 \mathrm{BU}$ [38]. There are strong proponents of the exclusive use of high-dose ITI because of longstanding institutional experience [51]. However, consideration of the comparative cost-effectiveness and reduced morbidity associated with lower-dose, non-daily regimens [56] may be crucial to the broader availability of ITI in both the developed and developing world. To this end, the ongoing I-ITI study is evaluating the effect of FVIII dose on the overall ITI success rate and time to success by randomizing 150 good-risk, severe haemophilia A subjects to receive FVIII doses of either $200 \mathrm{IU} \mathrm{kg}^{-1}$ daily or $50 \mathrm{IU} \mathrm{kg}^{-1}$ three times weekly 
for up to 33 months [23]. The need for reliable, unbiased data is crucial, and it is recommended that all ITI patients be enrolled either in a prospective, randomized clinical trial or an international registry $[57,58]$.

In contrast to good-risk patients, dose may be important for 'poor-risk' patients, defined as those with a peak historical inhibitor titre $>200 \mathrm{BU}$ and/or a pre-ITI titre higher than $10 \mathrm{BU}$ and/or time since inhibitor diagnosis exceeding 5 years. According to the meta-analysis of the IITR and NAITR data, only high-dose regimens ( $\left.\geq 200 \mathrm{IU} \mathrm{kg}^{-1} \mathrm{day}^{-1}\right)$ offer the most reasonable chance of ITI success for individuals with poor prognostic parameters [38]. Only one of $23(4 \%)$ poor-risk patients treated with daily doses of $<200 \mathrm{IU} \mathrm{kg}^{-1}$ were successfully tolerized, whereas higher doses effectively eradicated inhibitors in 12 of 18 patients $(67 \%)$. ITI-naive patients with poor prognoses will be eligible to participate in the Rescue Immunotolerance (RESIST) Study, a companion trial to the I-ITI study, that is scheduled to start in the near future and will randomize patients to receive high-dose ITI (200 IU kg-1 $\left.\mathrm{day}^{-1}\right)$ with either recombinant FVIII (rFVIII) or a plasma-derived von Willebrand factor (VWF)-containing FVIII concentrate [19]. Enrollment of poor-risk patients in prospective, comparative clinical trials and a trial of dose maximization among those who fail low-dose ITI is strongly recommended.

\section{Consensus recommendations for ITI dosing (Fig. 1)}

1 Among good-risk patients (i.e. peak historical titre $<200 \mathrm{BU}$, pre-ITI titre $<10 \mathrm{BU},<5$ years since diagnosis), no dosing regimen has been shown to be superior to another. These patients may be eligible to participate in the I-ITI study (level IIb).

2 Among poor-risk patients (i.e. peak historical titre $>200 \mathrm{BU}$ and a pre-ITI titre $>10 \mathrm{BU}$ and/or $>5$ years since inhibitor diagnosis), the evidence suggests a higher success rate with the use of highdose regimens $\left(\geq 200 \mathrm{IU} \mathrm{day}^{-1}\right)$. These patients may be eligible to participate in the RESIST Study (level IIb).

\section{FVIII product}

The choice of FVIII product to achieve inhibitor eradication is another matter of debate. High ITI success rates (73-91\%) have been reported for patients treated with monoclonal (plasma-derived human FVIII produced using immunoaffinity chromatography and a monoclonal antibody to FVIII) and recombinant FVIII concentrates [42,44,59-62], yet some data suggest that plasma-derived FVIII (pdFVIII) concentrates rich in VWF increase the likelihood of successful tolerization.

A longitudinal study conducted at the HTC in Frankfurt, Germany, showed that success rates using a high-dose ITI protocol had declined from 91\% (19/21 patients) to $37.5 \%$ (six of 16 patients) with the introduction of high-purity concentrates $[63,64]$. However, when patients who had an unsatisfactory response to ITI using monoclonal or recombinant FVIII were switched to concentrates containing high amounts of VWF, eight of $10(80 \%)$ experienced complete eradication of their inhibitors. Similarly, a compilation of data on ITI therapy from HTCs in Bonn and Bremen, Germany, showed that before 1990, ITI was successful in 44 of 51 patients $(86 \%)$ treated exclusively with intermediate-purity FVIII/ VWF concentrates [65]. Success rates dropped to $55 \%$ between 1990 and mid-1999, when highpurity FVIII products without VWF were primarily used. With the resumed use of FVIII/VWF concentrates in July 1999 , success rates increased to $71 \%$. Specifically, 23 of 28 patients $(82 \%)$ undergoing ITI with FVIII/VWF were successfully tolerized, compared with six of 14 patients $(43 \%)$ treated with rFVIII.

Other researchers have also observed the enhanced efficacy of VWF-containing concentrates in achieving tolerization. Orsini et al. [66] reported that ITI was successful in eight of eight patients undergoing ITI with a high-purity FVIII/VWF product. In addition, prospective surveillance conducted by Gringeri showed that six of 13 patients at high risk for a poor response to ITI, including three patients who had previously failed ITI, were successfully tolerized using a high-purity FVIII/VWF concentrate [67]. The remaining seven patients, who were still undergoing ITI, converted from high- to lowresponder status.

One explanation for these favourable findings is that VWF, in addition to being a critical component of haemostasis [68] and playing key roles in FVIII function, production and stabilization [68,69], may also modulate FVIII immunogenicity [70], thereby influencing ITI outcome. Inhibitors react with and bind to active sites on the FVIII molecule, primarily with epitopes in the A2, A3, C1 and C2 domains [71] VWF binds to similar epitopes on the FVIII molecule as inhibitors directed against the $\mathrm{C} 2$ domain, which may result in epitope masking [72,73]. Consequently, a small subset of FVIII antibodies may be less inhibitory to FVIII complexed with VWF compared with monoclonal and recombinant FVIII products [74-77]. 
The potentially beneficial effects of VWF notwithstanding, immune tolerance is a multifactorial process, and variables other than VWF contribute to differences in success rates [73]. Moreover, it is unclear if a switch from monoclonal or recombinant FVIII to VWF-containing concentrates was responsible for successful tolerization or if inhibitor eradication simply resulted from an extended duration of ITI. In other words, the patients may have become immune tolerant had their original treatment regimens been continued longer. Meta-analysis of data from the IITR and NAITR found no association between outcome and treatment product [38]. In the IITR, $96 \%$ of patients were treated with intermediate-purity products; in the NAITR, monoclonal and recombinant products were predominantly used. Yet the distribution of success and failure was equivalent: $70 \%$ success, $30 \%$ failure. Furthermore, no prospective, randomized trial has compared VWF/FVIII with monoclonal or recombinant concentrates. Thus, at the present time, there is no definitive evidence demonstrating the superiority of any FVIII product, although the RESIST trial may provide this data in the future. Most patients are tolerized using the product they were receiving when they developed an inhibitor [15]. This approach is effective, and switching to another FVIII product for de novo ITI is not recommended.

Consensus recommendations for FVIII product (Fig. 1)

1 ITI is successful using FVIII products with and without VWF (level IIb).

2 No data support the superiority of any FVIII product (level IIb).

3 Most patients are tolerized with the same FVIII product in use at the time of inhibitor detection. This approach works, and there is no evidence to support switching to another FVIII product for de novo ITI (level IIb).

\section{Immunoadsorption}

Extracorporeal immunoadsorption, a component of the Malmö ITI protocol when necessary [40] involves selectively removing immunoglobulins and immune complexes using Staphylococcal protein A or antiimmunoglobulin columns [78]. The process, which eliminates approximately $70-90 \%$ of circulating inhibitory antibodies [79], appears to be more useful for patients with acquired haemophilia than for those with severe congenital haemophilia with inhibitors [80]. Accordingly, there is no role for immunoadsorption as a first-line component of ITI.
Consensus recommendations for immunoadsorption (Fig. 1)

1 There is no role for immunoadsorption as a firstline component of ITI (level IIb).

\section{Prophylaxis during ITI}

The results of the randomized controlled US Joint Outcome Study, reported by Manco-Johnson in 2005, established the efficacy of FVIII prophylaxis in preventing joint damage in patients with severe haemophilia A without inhibitors [81]. Other investigators have shown that FVIII prophylaxis indirectly improves academic performance [82] and quality of life [83]. Increasingly, prophylaxis with bypassing therapy is being used for patients with FVIII inhibitors, as they are at increased risk for joint disease and severe haemorrhage [16] owing to the difficulty in controlling bleeding episodes [84].

FEIBA has been a component of the Bonn ITI regimen for 30 years [17], and it is currently used in patients at high risk for bleeding [51] Kreuz et al. [85] prospectively evaluated FEIBA prophylaxis in 22 children, aged 0.1-6 years, with high-titre inhibitors ( $>5 \mathrm{BU})$ undergoing ITI. FEIBA was administered at a dose of $50 \mathrm{U} \mathrm{kg}^{-1}$ daily, with the dosage increased up to $100 \mathrm{U} \mathrm{kg}^{-1}$ twice daily for breakthrough bleeding. The median annual incidence of joint bleeding during FEIBA prophylaxis was one (range, 0-6), and no patient suffered a life-threatening haemorrhage. No evidence of arthropathy was seen in six of eight patients evaluated radiographically; and in the remaining two patients, joint pathology was minimal. Valentino prospectively studied three inhibitor patients, aged 3.7-24.1 years, who received concomitant FEIBA prophylaxis at a daily dose of $100 \mathrm{U} \mathrm{kg}^{-1}$ during ITI [86]. The incidence of joint bleeding prior to the initiation of prophylactic therapy ranged from 2.5 to 4.08 per 100 days and declined to $0.0-1.42$ per 100 days during treatment, a reduction of $65-100 \%$. FEIBA was well tolerated and did not cause thrombosis.

Historically, rFVIIa is less likely to be used for prophylaxis outside of the perioperative setting because of its shorter half-life (approximately $3 \mathrm{~h}$ in adults [87] and even more rapid clearance rates in children [88]), compared with FEIBA (4-7 h) [89]. Although future clinical practice may change subsequent to the pilot data presented by Konkle et al. [90] on the efficacy of rFVIIa in inhibitor patients not concomitantly receiving ITI, a current review of the literature identified only one case study describing the successful use of rFVIIa prophylaxis during immune 
tolerance. Saxon et al. [91] reported that rFVIIa at a dose of $90 \mu \mathrm{g} \mathrm{kg}^{-1}$ once daily significantly reduced the number of target joint bleeding episodes in a preschool-aged boy undergoing ITI. The efficacy of rFVIIa in this patient may indicate that rFVIIa may have a longer biologic effect than is indicated by its half-life, according to the authors [91].

Potential drawbacks to the concurrent use of bypassing agent prophylaxis during ITI include the high cost and risk of thrombosis [92]. When bypassing therapy is used outside the ITI setting, thrombotic risk is very low. Whether the same holds true when these products are used concurrently with ITI is unknown.

By avoiding an inflammatory environment in which the tolerogenic delivery of FVIII is not possible, prophylaxis during immune tolerance may prevent major haemorrhage, thereby shortening the duration of ITI and improving the likelihood of success. However, data supporting such a hypothesis are limited. In patients undergoing immune tolerance who experience early joint bleeding or intracranial haemorrhage $(\mathrm{ICH})$, prophylaxis with a bypassing agent may be considered. The dose of FEIBA recommended based on reports of bypassing-agent prophylaxis during ITI $[85,86,91]$ and outside the ITI setting $[93,94]$ is $50-200 \mathrm{U} \mathrm{kg}^{-1}$ every day to twice weekly, and the recommended dose of rFVIIa is 90-270 $\mu \mathrm{g} \mathrm{kg}^{-1}$ daily [90]. The higher ends of the dosing ranges should be used for prophylaxis following ICH because of the significant risk of recurrent bleeding [95] FVIII recovery should be monitored frequently once the inhibitor titre drops to $10 \mathrm{BU}$ or below (following anamnesis triggered by ITI initiation). In an attempt to prevent the sporadic development of catheter-associated vessel thrombosis that has been reported with the concurrent use of ITI and bypassing agents [96], it is the consensus opinion that prophylaxis with bypassing agents should be discontinued when any level of FVIII recovery is detected.

When ITI is postponed to allow the inhibitor titre to decline to $<10 \mathrm{BU}$, FEIBA is not recommended for the first-line prophylaxis because of its potential to protract anamnesis [18]. The use of rFVIIa is preferred in this setting at a recommended dose of 90-270 $\mu \mathrm{g} \mathrm{kg}^{-1}$ daily.

Consensus recommendations for prophylaxis during ITI (Fig. 1)

1 Prophylaxis should be considered if patients continue to bleed frequently while awaiting or on ITI (level III).
$2 \mathrm{rFVII}$ at a dose of $90-270 \mu \mathrm{g} \mathrm{kg}^{-1}$ daily is preferred for prophylaxis when ITI is delayed to allow the inhibitor titre to decline to $<10 \mathrm{BU}$ (level IV).

3 Prophylaxis with FEIBA (50-200 $\mathrm{U} \mathrm{kg}^{-1}$ daily to twice weekly) or rFVIIa $\left(90-270 \mu \mathrm{g} \mathrm{kg}^{-1} \mathrm{day}^{-1}\right.$ ) may be considered for patients undergoing ITI who experience early joint bleeding or ICH (level III).

4 Monitor FVIII recovery when the inhibitor titre drops to $10 \mathrm{BU}$ (level IV).

5 Discontinue bypassing therapy at any level of FVIII recovery (level IV).

\section{Central venous access device issues}

General recommendations

Uninterrupted and uncomplicated venous access is essential in children undergoing ITI. Peripheral venipuncture is the first choice [97], and some HTCs initially attempt immune tolerance using regimens that involve less frequent FVIII administration, as this may facilitate peripheral venipuncture [18]. Nonetheless, central venous access devices (CVADs) are often necessary for ITI in young children, particularly for high-dose regimens [97].

Two major types of long-term CVADs are available: tunnelled and fully implantable (referred to as ports) and tunnelled external catheters [98]. Among haemophilia patients receiving long-term therapeutic interventions, subcutaneously implanted single-reservoir ports are the most commonly used CVADs [99]. In patients without inhibitors, ports are preferable to external devices [97] because they are less likely to become infected by pathogens than are external catheters [100]. The panel supports this recommendation for inhibitor patients as well. Published guidelines [97] for catheter care should be meticulously followed by physicians and nurses. Furthermore, because long-term CVAD use requires considerable commitment from caregivers and patients, comprehensive education should be provided before ITI is initiated and reinforced periodically thereafter.

\section{Complications}

\section{Infection}

Infection is the major complication associated with CVADs used in haemophilia $[99,101,102]$, and it is the most common cause for their removal [98] CVAD infection occurs more frequently in haemophilia patients with inhibitors [98,101,103], possibly due to subcutaneous bleeding around the port that facilitates entrance of Gram-positive bacteria 
through the skin, a situation unique to the pediatric inhibitor population [104]. Infection rates are particularly high among inhibitor patients undergoing ITI, ranging from $50 \%$ to $83 \%$, according to a review by van den Berg et al. [104]. Increased CVAD access for daily FVIII administration may explain this higher incidence [101]. The development of catheter infections may cause interruptions in ITI that prolong tolerization or lead to treatment failure by provoking an anamnestic increase in the inhibitor titre $[15,18]$.

Preliminary data from the I-ITI study confirm that CVAD infection occurs frequently during immune tolerance [23,105]. Thirteen of 36 subjects $(36 \%)$ enrolled in the trial as of January 2006 had developed at least one catheter infection. Furthermore, ITI success rates were observed to be lower, failure rates higher, and response to treatment slower in these individuals than in subjects without infection. Specifically, five subjects $(38 \%)$ with infection achieved a negative inhibitor titre after a median of 14 months on ITI, compared with 17/22 uninfected patients $(77 \%)$ who achieved the same status after a median of 7.5 months. Another five (38\%) of the 13 subjects with a history of CVAD infection have thus far met the criteria for ITI failure. Published guidelines on CVAD care [98] provide clinical strategies for the prevention of catheter-related infection as well as catheter management in the presence of a single or recurrent infection.

\section{Thrombosis}

Thrombotic events associated with CVADs may result in catheter occlusion or catheter-related thrombosis [98], and the risk of such events increases with the duration of catheter placement [106]. A meta-analysis by Valentino et al. [98] of 48 studies involving a total of 2704 patients and 2973 CVADs found a pooled incidence of thrombosis of 0.056 per 1000 catheter days. The presence of an inhibitor did not significantly affect thrombosis incidence, in contrast to infection rate.

When a CVAD-related deep vein thrombosis (DVT) is detected, the panel recommends discontinuing bypassing prophylaxis (if used) and reviewing infusion techniques with the family. Consideration should be given to removing the catheter and transitioning to peripheral venipuncture and also to modifying the ITI regimen. Clot resolution may occur spontaneously after catheter removal or even when the catheter is left in place [98]. Patients should be monitored closely, and if a severe clot fails to resolve or if it progresses, catheter-directed thrombolysis or a short course of anticoagulation should be considered.

\section{Mechanical dysfunction}

Mechanical problems may also occur with ports [98], although this complication is less common than infection or thrombosis [101]. Mechanical dysfunction may lead to catheter removal [101], and all such events should be reported to the appropriate governmental regulating agency.

\section{Arteriovenous fistulae}

An infectious or thrombotic complication may limit the long-term use of a CVAD [107]. Arteriovenous fistulae (AVF), considered the vascular access of choice for haemodialysis patients because of their durability and low complication rate [108], are a protocol-driven option for venous access in children aged 1 year and older who have experienced repeated CVAD failure. Santagostino et al. [107] prospectively studied the long-term safety and feasibility of AVF in 27 children with severe haemophilia A, including 14 with inhibitors. The AVF were regularly and successfully used at home by 26 patients $(96 \%)$ for a median of 29 months. Venous thrombosis occurred in one patient after 9 months, but symptoms spontaneously disappeared, and the AVF was used for an additional 9 months.

Adapting AVF to the requirements of children with haemophilia requires surgical expertise, and long-term follow-up with ultrasonography and echocardiography is necessary. All AVF should be dismantled as soon as peripheral veins provide adequate vascular access. Although ITI can continue if an AVF-related thrombosis occurs, prophylactic bypassing therapy should be stopped.

\section{Consensus recommendations for CVAD issues (Fig. 1)}

1 Use peripheral venous access whenever possible (level IV).

2 Ports are preferable to external catheters because of the significantly lower risk of infection (level IV).

3 Follow published guidelines for catheter care and infection prevention (level IV).

4 Instruct families on CVAD techniques before starting ITI (level IV).

5 If an infection develops, follow published guidelines on CVAD management (level IV).

6 If a CVAD-related DVT occurs, discontinue bypassing prophylaxis (if used) and review infusion techniques with family (level IV) in addition to the following:

a. Consider removing the catheter and transitioning to peripheral venipuncture (level IV).

b. Consider modifying the ITI regimen and future bypass therapy regimens (level IV). 
7 Monitor closely for clot resolution (level IV).

8 If a severe clot fails to resolve or progresses, consider (level IV)

a. Catheter-directed thrombolysis

b. A short course of anticoagulation

9 An AVF is a protocol-driven option for venous access in children at least 1 year of age who have experienced repeated CVAD failure (level IV).

a. Surgical expertise is essential in adapting AVF to the requirements of children with haemophilia (level IV)

b. Long-term follow-up of AVF with ultrasonography and echocardiography is necessary (level IV)

c. Dismantle an AVF as soon as peripheral veins provide adequate vascular access (level IV).

d. ITI can continue if an AVF-related thrombosis develops, but stop prophylactic bypassing therapy (level IV).

\section{Incomplete or lack of response to ITI}

The time to ITI success is extremely variable, ranging from a few months to two or more years [18]. In the NAITR, while successful outcomes were achieved more quickly in patients who received FVIII doses of at least $50 \mathrm{IU} \mathrm{kg}^{-1}$ daily, the majority of patients treated with lower doses were successfully tolerized, albeit more slowly [26]. Thus, one strategy for patients who demonstrate no response or an incomplete response to ITI is to give the current treatment regimen additional time to produce results, particularly if a low-dose regimen is being used for reasons of preferential or default use of peripheral access. In the IITR, daily doses of at least $200 \mathrm{IU} \mathrm{kg}^{-1}$ were associated with statistically significantly higher success rates [55]. Although these data cannot be extrapolated to second-line or salvage ITI strategies, an alternative approach used in clinical practice is to maximize the ITI dose.

A switch to an intermediate-purity VWF-containing FVIII product may be an option for patients whose response to immune tolerance using monoclonal or recombinant FVIII is suboptimal. Given the small repository of published evidence suggesting that VWF-containing concentrates improve the likelihood of successful tolerization [64-67], coupled with the predominant use of intermediate-purity products in the IITR to achieve the reported outcome with the first-line ITI [22], consideration may be given to changing to a FVIII/VWF product.

The addition of rituximab to the ITI regimen may improve response rates in patients who remain difficult to tolerize $[109,110]$. Rituximab is a mono- clonal antibody against CD20-positive B cells that has shown promise in the treatment of acquired haemophilia (autoantibodies) [111,112]. However, published experience with this agent in the treatment of alloantibodies associated with congenital haemophilia is limited to approximately two dozen patients [109,113-123]. Among these patients treated with rituximab at a dose of $375 \mathrm{mg} \mathrm{m}^{-2}$ given once weekly for 4 weeks, 16 (73\%) achieved an undetectable inhibitor based on the Bethesda assay. After 90 days-2 years of follow-up, $55 \%$ remained in remission. Interpretation of these data is hampered by the variable regimens used, some of which included steroids, vincristine, or cyclosporine $[116,117]$, and the likelihood of preferential reporting of positive outcomes. Nonetheless, the 22 patients compose a group with poor prognostic indicators, and a $55 \%$ response rate is encouraging. Treatment of patients using a standardized protocol and the reporting of consecutive patients is a necessary first step to collecting interpretable data.

Consensus recommendations for managing incomplete or lack of response to ITI (Fig. 1)

1 Continue the initial ITI regimen, particularly if a low-dose regimen is being used for reasons of preferential or default use of peripheral access (level IV).

2 Maximize the ITI dose if a lower dose regimen is being used and adequate venous access exists (level IV).

3 Consider switching to a FVIII/VWF product if ITI was initiated with a monoclonal or recombinant product (level III).

4 Consider adding rituximab or another immunemodulating drug to the current regimen (level III).

\section{ITI outcome definitions}

\section{Success}

\section{Pharmacokinetic parameters}

The pharmacokinetic parameters currently used to define ITI success in patients with severe and mild haemophilia A were established by consensus at the Second International Conference on Immune Tolerance held in Bonn, Germany, in 1997. These parameters include an undetectable inhibitor level $(<0.6 \mathrm{BU})$, FVIII plasma recovery $\geq 66 \%$ of predicted, FVIII half-life $\geq 6 \mathrm{~h}$ after a 72 -h FVIII washout period, and the absence of anamnesis upon further FVIII exposure [57]. This definition has been adopted by the I-ITI study [23], which defined partial 
success as a reduction of the inhibitor titre to $<5 \mathrm{BU}$; FVIII recovery of less than $66 \%$ of predicted; and FVIII half-life of $<6 \mathrm{~h}$ after a 72 -h FVIII washout period associated with clinical response to FVIII therapy and no increase in the inhibitor titre exceeding 5 BU over a 6 -month period of on-demand treatment or 12 months of prophylaxis [124].

Potential alternative definitions of ITI success based on measurable parameters of immunologic tolerance and/or the emerging biochemistry of FVIII clearance were explored by the panel. However, none were thought to be sufficiently definitive at this time to supplant or complement the current definition.

Cost-effectiveness as a defining parameter of ITI success ITI success may also be defined on the basis of its cost-effectiveness. The majority of direct costs associated with the care of haemophilia patients are attributable to clotting factor replacement therapy [125]. These costs are greater in patients with hightitre inhibitors because they require bypassing therapy, which is more expensive. Costs may further increase as a result of the outlier effect caused by a small percentage of inhibitor patients who require a disproportionate amount of treatment.

An analysis of 314 patients enrolled in the IITR found that $70 \%$ of patients with good prognostic indicators (i.e. pre-ITI titre $<10 \mathrm{BU},<5$ years since inhibitor diagnosis, high-dose ITI regimen) achieved tolerance within 1 year, whereas those with poor prognostic indicators required 2.5 years of treatment to achieve comparable results [126]. The total cost of ITI in a patient with good prognostic indicators was estimated to range from US $\$ 900000$ to $\$ 1.8$ million, depending on whether plasma-derived or recombinant product was used. This cost increased to an estimated US $\$ 6.3$ million-12.6 million in a patient with poor prognostic indicators.

Colowick et al. [127] modelled the cost-effectiveness of ITI as a long-term strategy for inhibitor management. Their Markov model showed that while the cost of immune tolerance in a 5-year-old child approached \$1 million, successful ITI would result in a lifetime reduction in the need for replacement clotting factor (including bypassing therapy) of $\$ 1.7$ million. Moreover, successful tolerization increased life expectancy by 4.6 years.

An alternative strategy to the Markov decision model developed by Colowick is to compare ITI intervention costs and outcomes, whether or not successful, with those of patients with lifelong hightitre inhibitors. Such a comparison would require meticulously gathered cost and quality of life (QOL) data from representative cohorts of inhibitor patients. Recently completed studies that have captured some of this information [128-131] may make this feasible in the future. Cost-effectiveness as a measure of ITI success is also being examined by the I-ITI study. At the current time, however, cost-effectiveness parameters could not be incorporated into a definition of ITI success.

\section{Failure}

\section{Pharmacokinetic parameters}

The pharmacokinetic definition of ITI failure currently adopted by the I-ITI study was also established by consensus at the Second International Conference on Immune Tolerance. It is defined as failure to achieve a full or partial success within 33 months or the failure to achieve an ongoing reduction in the inhibitor titre of at least $20 \%$ during each interim, non-overlapping, 6-month period after the first 3 months of ITI (in the absence of documented infection) [124]. This definition implies that 9 months is the minimum treatment period and 33 months is the maximum reasonable duration of unsuccessful ITI.

In clinical practice, ITI is sometimes continued beyond 33 months, and a resistant minority of patients may take 3 years or more to achieve tolerance [132]. Clinical improvement, including fewer bleeding episodes and improved QOL, may favour continuing ITI [128]. However, economic considerations often determine how long ITI is pursued [20].

Potential alternative definitions of ITI failure based on measurable parameters of immunologic tolerance and/or the emerging biochemistry of FVIII clearance were discussed. However, none were thought to be sufficiently definitive at this time to supplant or complement the current definition.

\section{Consensus recommendations for defining ITI outcome} (Fig. 1)

1 Pharmacokinetic parameters of success: (level III) a. A normal inhibitor titre

b. Normal FVIII recovery ( $\geq 66 \%$ of predicted)

c. Normal FVIII half-life ( $\geq 6$ h) after a 72 -h FVIII washout period

d. Absence of anamnesis upon further FVIII exposure

2 Pharmacokinetic parameters of partial success: (level III)

a. An inhibitor titre $<5 \mathrm{BU}$

b. FVIII recovery $<66 \%$ of predicted 
c. FVIII half-life $<6 \mathrm{~h}$ after a 72 -h FVIII washout period

d. Clinical response to FVIII

e. No increase in the inhibitor titre $>5$ BU over a 6-month period of on-demand therapy or a 12 -month period of prophylaxis

3 Pharmacokinetic parameters of failure: (level III)

a. Failure to fulfil criteria for full or partial success within 33 months

b. Less than a $20 \%$ reduction in the inhibitor titre for any 6-month period during ITI after the first 3 months of treatment, which implies that

i. 9 months is the minimum period for ITI; ii. 33 months is the maximum duration of ITI, although the decision may be made to continue immune tolerance

\section{Immune tolerance induction in patients with mild haemophilia A}

Compared with alloantibodies that develop in severe FVIII deficiency, inhibitors associated with mild FVIII deficiency tend to arise later in life, reflecting the infrequency of bleeding episodes in this patient population and the resultant decreased need for treatment [133].

Inhibitors in mild haemophilia A are often associated with a familial predisposition and the presence of high-risk mutations that induce a conformational change in the FVIII molecule resulting in a functional FVIII defect [133]. In a cohort of mild haemophilia A patients with inhibitors described by Hay et al. [134], 41\% of treated family members also had a history of FVIII inhibitors. High-risk mutations in the FVIII gene and intensive replacement therapy, such as for surgery, trauma, or muscle bleeding, are other risk factors for inhibitor development in mild haemophilia A. An inhibitor titre and baseline FVIII level should be obtained for all patients with mild haemophilia A and a family history of inhibitors or when genotyping reveals the presence of highrisk mutations. Screening should be repeated at each clinic visit if the patient has received FVIII in the interim and should be performed both preoperatively and postoperatively. When patients with mild haemophilia A undergo surgery, FVIII replacement therapy should be closely monitored, as it is common for inhibitors to present with postoperative haemostatic failure [133].

Bleeding manifestations associated with mild haemophilia A and inhibitors are similar to those observed with acquired antibodies (alloantibodies)
$[135,136]$. Patients may develop severe and persistent bleeding, often in soft tissue and the gastrointestinal and genitourinary tracts, that is relatively or completely refractory to FVIII replacement therapy and may be life-threatening [133]. Desmopressin acetate (DDAVP) and other therapies that avoid FVIII exposure (e.g. bypassing agents) should be used for the management of bleeding episodes in patients with mild haemophilia $\mathrm{A}$ and inhibitors in circumstances where the response to testing is adequate. Both low-titre and high-titre alloantibodies may disappear spontaneously but may recur when the patient is re-exposed to FVIII [133].

Inhibitors in patients with mild haemophilia A also resemble autoantibodies in their poor response to traditional ITI [136]. The Malmö regimen may be more effective than other protocols in completely eradicating inhibitors associated with mild haemophilia A, according to published reports, but the number of patients reported on is too small to reach any firm conclusions [133]. If immune tolerance is being considered, it is advisable to first rechallenge the patient with FVIII, keeping in mind that a lack of anamnesis does not mean the inhibitor will not return upon subsequent rechallenge $[133,135]$. No recommendations can be made for ITI, but if treatment is initiated, the data should be reported to national and international registries. A retrospective collection of data is currently being performed in France and Belgium, in an effort to increase knowledge and improve the understanding of mild haemophilia A complicated by an inhibitor [135]. Preliminary results from this group of patients, who have a significantly lower median age than that reported by Hay [133], suggest a higher response rate to ITI [135]. Nonetheless, these success rates are still lower than those reported for severe haemophilia A.

\section{Consensus recommendations for ITI in patients with mild haemophilia A (Fig. 2):}

1 There can be no recommendations for ITI in mild haemophilia A.

2 If ITI is initiated, report data to national and international registries.

\section{Immune tolerance induction in patients with haemophilia B}

Approximately $3 \%$ of patients with haemophilia B develop inhibitors [3], and more than $80 \%$ of these 


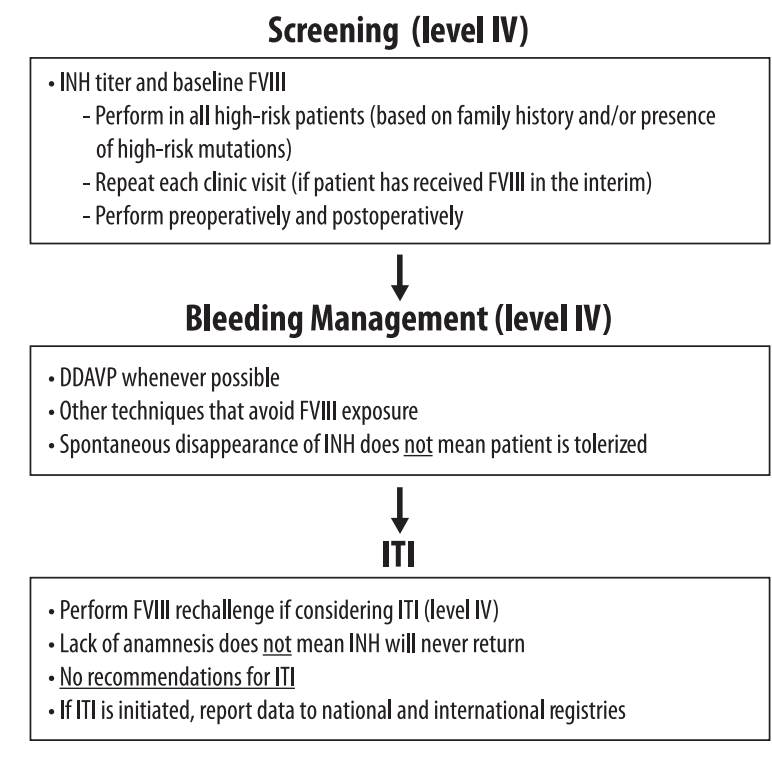

$\mathrm{INH}=$ inhibitor; $\mathrm{DDAVP}=$ desmopressin acetate; $\mathrm{ITI}=$ immune tolerance induction.

Fig. 2. Mild haemophilia A: recommended management algorithm.

alloantibodies are high-responding [137]. The development of inhibitors in patients with haemophilia B is generally associated with the absence of FIX antigen caused by large or complete deletions or major derangements of the FIX gene [138]. These mutations are also linked to severe allergic anaphylactoid or life-threatening anaphylactic reactions to FIX concurrent with the appearance of an inhibitor [139]. This is a well-recognized phenomenon that occurs almost exclusively in conjunction with FIX inhibitor development.

The aetiology of allergic reactions remains unclear. The small molecular mass of the FIX protein $(55000 \mathrm{kDa})$ accounts for its extracellular distribution, and this feature of FIX may contribute in some way to hypersensitivity reactions in haemophilia B patients [139]. A second theory ties anaphylactic reactions to excessive immune complex formation resulting from a large infused load of exogenous FIX protein with each treatment. The standard dose of FIX is $40-80 \mathrm{IU} \mathrm{kg}^{-1}$, which exposes patients to $200-400 \mu \mathrm{g}$ of exogenous protein. In contrast, standard dosing for FVIII deficient patients is 25$50 \mathrm{IU} \mathrm{kg}{ }^{-1}$, which exposes them to just $2.5-5.0 \mu \mathrm{g}$ of factor $[138,139]$. Finally, molecular genetic characterization of FIX inhibitors reported to the registry showed that FIX inhibitor patients whose haemophilia B resulted from complete gene deletions had a $26 \%$ risk for anaphylactic reactions [140]. It has been postulated that since FIX gene deletions are sometimes extremely large [141], codeletion of immune response modifier genes could trigger allergic responses in otherwise susceptible patients [139].

To date, the immunology of both FIX inhibitor development and its associated allergic phenomena have been difficult to study in a definitive way. However, FIX genotyping may identify children at greatest risk for inhibitor development and anaphylaxis [138] and should be performed for every patient with severe haemophilia B at the time of initial presentation [58].

Allergic-type reactions in patients with inhibitors preclude the use of FIX-containing products unless patients are thoroughly desensitized. Consideration may be given to desensitization to improve the management of bleeding episodes, but the response is inconsistent. Moreover, even after patients become desensitized, most continue to have recurrent allergic reactions to FIX that require premedication with antihistamines and steroids [138].

The success of ITI in eradicating FIX inhibitors is low, particularly in patients with the allergic phenotype [22]. Among 16 haemophilia B subjects in the NAITR who completed ITI, five had a successful outcome using FIX therapeutic dosing regimens that ranged from 43 to $200 \mathrm{IU} \mathrm{kg}^{-1}$ daily [22]. This group included one patient with an inhibitor-associated allergic phenotype and three whose inhibitors were not allergic in nature. Adverse events were reported during 11 of 17 (65\%) ITI courses administered to individuals with FIX inhibitors, a frequency 10 times higher than that for persons with FVIII inhibitors. The 11 courses were complicated by 14 reactions to treatment. Allergic reactions accounted for 11 of 14 adverse events and occurred in the 10 registry subjects already known to exhibit allergic reactions to FIX replacement therapy subsequent to the development of inhibitors. Of those 11, three were severe reactions and the cause of premature ITI cessation. Overall, allergic reactions represented the major reason for failure in at least four of 11 unsuccessful courses of ITI in haemophilia B.

The International Society on Thrombosis and Haemostasis (ISTH) Registry on FIX Inhibitors data reveal that ITI was successful in only five of the 34 patients $(15 \%)$ in whom it was attempted, and two of those patients had low-responding inhibitors [137]. Moreover, 13 of the 34 patients (38\%) developed nephrotic syndrome during ITI [137]. An association between allergic reactions to FIX in inhibitor patients undergoing ITI and the development of nephrotic syndrome was also noted in the NAITR cohort [22]. In all, three of 10 such subjects developed nephrotic syndrome while undergoing immune tolerance, accounting for three of 14 reported 
adverse events. This complication is primarily associated with a history of allergic phenotype inhibitors [142,143] and has been observed with all FIX products [143]. Although there have been reports of return to normal renal function with cessation of ITI alone, corticosteroid therapy has been required by some patients with variable success [142]. Nephrotic syndrome has not been reported in patients undergoing ITI for FVIII inhibitors, which may reflect the lower amounts of FVIII in plasma, compared with FIX (approximately 1:50 on a $\mathrm{mg} \mathrm{mL} \mathrm{m}^{-1}$ basis) $[137,142]$.

An alternative immunosuppressive strategy for the treatment of FIX inhibitors described by German researchers has been successful in a single patient [144]. A 5-year-old boy with severe haemophilia B underwent ITI using a regimen that included mycophenolate-mofetil, dexamethasone and intravenous immunoglobulin together with high-dose FIX. After 8 weeks, his inhibitor had disappeared, FIX recovery and half-life had normalized, and he did not develop nephrotic syndrome.

Desensitization may be needed prior to ITI initiation, but this process does not transform risk from poor to good, nor does it preclude the development of nephrotic syndrome. The decision to attempt ITI for FIX inhibitors must be very carefully weighed against the relatively high-risk of adverse reactions and the relatively low likelihood of success, particularly in those patients whose inhibitor is associated with an allergic phenotype [58]. Consequently, if immune tolerance is initiated, particularly in that subset of patients, physicians are urged to proceed with great caution and to perform routine urinalyses during ITI to detect proteinuria and early nephrotic syndrome [138].

Consensus recommendations for ITI in patients with haemophilia B (Fig. 3):

1 There can be no recommendations for ITI in haemophilia B.

2 If ITI is initiated, proceed with caution and perform routine urinalyses during treatment to evaluate for nephrotic syndrome (level IV).

3 Parameters for ITI success and failure established by consensus for FVIII inhibitors cannot be applied to define success in haemophilia B.

\section{Research priorities}

Immune tolerance is a costly process that is unsuccessful in approximately $20-40 \%$ of patients with
Screening

\begin{tabular}{|l|}
\hline - Genotyping essential (level IV) \\
\hline $\begin{array}{l}\text { - Consider desensitization of anaphylactoid patient to improve bleeding } \\
\text { control (level IV) }\end{array}$ \\
\hline $\begin{array}{l}\text { - Low success rates, particularly in patients with anaphylactoid phenotype (level IIb) } \\
\text { - Potential for nephrotic syndrome } \\
\text { - Desensitization may be needed prior to ITI initiation (level IV), but it does not } \\
\text { - Transform a poor-risk patient into a good-risk patient } \\
\text { - Preclude the development of nephrotic syndrome } \\
\text { - No recommendations for ITI } \\
\text { - If ITI is initiated, proceed with caution and perform routine urinalysis to evaluate } \\
\text { for nephrotic syndrome }\end{array}$ \\
\hline
\end{tabular}

$\mathrm{ITI}=$ immune tolerance induction.

Fig. 3. Haemophilia B: recommended management algorithm.

severe haemophilia A [136] and a far greater percentage of those with mild haemophilia $\mathrm{A}$ and haemophilia B [137]. Moreover, many patients are not candidates for ITI because of the presence of long-standing inhibitors, the expense of treatment, unfavourable risk-benefit ratios, or patient/family issues. Thus, inhibitory antibodies are persistent in a substantial number of individuals, severely jeopardizing their health and the quality of their lives. To design optimal and cost-effective therapies that prevent and treat inhibitors requires deepened understanding of the immunology of inhibitor formation and of the mechanisms that promote tolerance. The following high-priority research areas were identified by the International Consensus Panel:

\section{Immunologic aspects of inhibitor development}

Antibody formation against FVIII is a CD4-positive $\left(\mathrm{CD}^{+}\right) \mathrm{T}$ cell-dependent process that requires $\mathrm{T}$-cell interaction with antigen-presenting cells together with T-cell and B-cell interaction [145]. The failure to activate regulatory CD4+ cells may play a crucial role in the development of FVIII inhibitors and is an area that requires ongoing investigation [146].

\section{Immunology of FVIII tolerance}

Tolerance is an active process that can be both induced and antigen-specific [147]. Although the basic mechanisms of the immune response to FVIII in the setting of factor replacement therapy are being elucidated, further study is needed to clarify the relevance of these mechanisms in the context of successful ITI and, ultimately, gene therapy [146]. 


\section{Haemophilia and inflammatory cytokine mediator} genotypes

Haemophilia genotype and the genotype for host immune responses influence the risk of inhibitor development $[29,36]$. Whether these genotypes also influence the response to ITI is unclear and is a focus of ongoing investigations.

Role of FVIII dose in ITI success

This parameter is under intensive study and, it is hoped, will be clarified through the I-ITI study.

\section{Role of FVIII purity in ITI success}

In vitro experiments showed that VWF prevents the interaction of FVIII with endocytic receptors that degrade and eliminate FVIII from the circulation [148]. In these studies, increasing the molar ratio of VWF to FVIII above the physiologic ratio of 50:1 decreased the endocytosis of FVIII by dendritic cells. Increasing plasma concentrations of VWF may decrease the amount of FVIII presented to T lymphocytes, thereby reducing $\mathrm{T}$-cell activation. Findings from the RESIST trial and an ongoing German observational study by Kreuz and colleagues may determine if VWF/FVIII products improve ITI success rates or if VWF is simply a surrogate marker for other beneficial components present in pdFVIII. Other questions related to the role of VWF/FVIII interaction that may be explored:

1 The role of endogenous VWF levels on ITI success

2 Correlation of ABO blood grouping to ITI success

3 Differences in immunologic processing of VWFbound FVIII and unbound ('free') FVIII.

4 Differences in efficacy between high-purity pdFVIII and VWF-containing pdFVIII.

Role of infection, catheter infection and catheter thrombosis on ITI success

Both infection and thrombosis are common complications in patients with CVADs $[97,99,101,102]$. Their true impact on ITI success may be clarified in the I-ITI study.

Alternative strategies for treating bleeding episodes and inducing tolerance

Preclinical studies suggest that innovative strategies, such as bypassing inhibitors with human/porcine FVIII hybrid concentrates, blocking or neutralizing inhibitors using peptide decoys or anti-idiotypic antibodies, administering FVIII to the nasal or gut mucosa, and gene transfer technology, may enhance the management of bleeding events in inhibitor patients or improve the likelihood of successful tolerization. Clinical trials are needed to determine if the results obtained in the laboratory and in animals translate to success in patients.

\section{Immunologic definition of ITI success/failure}

Despite the ubiquitous use of pharmacokinetic parameters to define ITI success or failure, these parameters vary considerably among patients, and no firm evidence supports the defining values [57]. Furthermore, these parameters may be insufficient, given that approximately $4.3 \%$ of patients relapse after 'successful' ITI, according to registry data [55], an observation also noted in the ongoing IITI study. An immunologic definition of success may provide more useful information on when to start or stop ITI; how to tailor immune tolerance to the individual patient; how to maintain tolerance after ITI; and, in general, how to better manage haemophilia A and B.

\section{Immunology of inbibitor development and tolerance in mild haemophilia $A$}

It is unclear whether patients with mild haemophilia A who undergo 'successful' ITI achieve true tolerance, or if they remain at risk for anamnesis upon reexposure to FVIII. An immunologic definition may be essential to determine the success or failure of immune tolerance in this subset of inhibitor patients. The findings from the French-Belgium registry will be of critical importance in identifying useful inhibitor prevention and management strategies.

Alternative strategies for ITI in haemophilia B patients with inhibitors associated with anaphylaxis

ITI is unlikely to be successful in haemophilia B patients with the anaphylactoid phenotype $[138,149]$. Improving upon these success rates requires an enhanced understanding of the immunology of haemophilia B-related anaphylaxis.

\section{Conflict of interest statements}

D.M. DiMichele has acted as a paid consultant for Novo Nordisk, has received speaker fees from Baxter Bioscience and Bayer Healthcare and has received research funding from Baxter Bioscience, Bayer Healthcare and CSL Behring. Funding from the International Immune Tolerance Study referred to in this supplement is being provided by Baxter Bioscience, Bayer Healthcare, CSL Behring, Grifols and Wyeth. W.K. Hoots has acted as a paid consultant to Grifols, Wyeth, Baxter, Bayer, CLB Behring and Novo Nordisk Pharmaceuticals. He has 
received funding for research carried out in this work. M. Recht has acted as a paid consultant to Baxter and Wyeth. He has received research funding from Wyeth. All other authors have no conflicts of interests.

\section{References}

1 White GC, Rosendaal F, Aledort LM, Lusher JM, Rothschild C, Ingerslev J. Definitions in haemophilia. Recommendation of the scientific subcommittee on factor VIII and factor IX of the scientific and standardization committee of the International Society on Thrombosis and Haemostasis. Thromb Haemost 2001; 85: 560.

2 Brackmann $\mathrm{HH}$, Wallny T. Immune tolerance: high-dose regimen. In: Rodriguez-Merchan E.C., ed. Inhibitors in Patients with haemophilia. Oxford, England: Blackwell Science, Ltd, 2002: pp. 45-48.

3 Kessler CM. New perspectives in hemophilia treatment. Hematol Am Soc Hematol Educ Program 2005: 429-35.

4 UK Haemophilia Centre Doctors' Organisation (UKHCDO). The incidence of factor VIII and factor IX inhibitors in the hemophilia population of the UK and their effect on subsequent mortality, 1977-99. J Thromb Haemost 2004; 2: 1047-54.

5 Hay CR, Baglin TP, Collins PW, Hill FG, Keeling DM. The diagnosis and management of factor VIII and IX inhibitors: a guideline from the UK Haemophilia Centre Doctors' Organization (UKHCDO). $\mathrm{Br}$ J Haematol 2000; 111: 78-90.

6 Leissinger CA. Prevention of bleeds in hemophilia patients with inhibitors: emerging data and clinical direction. Am J Hematol 2004; 77: 187-93.

7 Hilgartner M, Aledort L, Andes A, Gill J. Efficacy and safety of vapor-heated anti-inhibitor coagulant complex in hemophilia patients. FEIBA Study Group. Transfusion 1990; 30: 626-30.

8 Negrier C, Goudemand J, Sultan Y, Bertrand M, Rothschild C, Lauroua P. Multicenter retrospective study on the utilization of FEIBA in France in patients with factor VIII and factor IX inhibitors. French FEIBA Study Group. Factor Eight Bypassing Activity. Thromb Haemost 1997; 77: 1113-9.

9 Key NS, Aledort LM, Beardsley D et al. Home treatment of mild to moderate bleeding episodes using recombinant factor VIIa (Novoseven) in haemophiliacs with inhibitors. Thromb Haemost 1998; 80: 912-8.

10 Shapiro AD, Gilchrist GS, Hoots WK, Cooper HA, Gastineau DA. Prospective, randomised trial of two doses of rFVIIa (NovoSeven) in haemophilia patients with inhibitors undergoing surgery. Thromb Haemost 1998; 80: 773-8.

11 Arkin S, Blei F, Fetten J et al. Human coagulation factor FVIIa (recombinant) in the management of limb-threatening bleeds unresponsive to alternative therapies: results from the NovoSeven emergency use programme in patients with severe haemophilia or with acquired inhibitors. Blood Coagul Fibrinolysis 2000; 11: 255-9.

12 Tjonnfjord GE. Activated prothrombin complex concentrate (FEIBA) treatment during surgery in patients with inhibitors to FVIII/IX: the updated Norwegian experience. Haemophilia 2004; 10 (Suppl. 2): 41-5.

13 Astermark J, Donfield SM, DiMichele DM et al. A randomized comparison of bypassing agents in hemophilia complicated by an inhibitor. Blood 2007; 109: 546-51.

14 Ho AY, Height SE, Smith MP. Immune tolerance therapy for haemophilia. Drugs 2000; 60: 547-54.

15 DiMichele D, Rivard G, Hay C, Antunes S. Inhibitors in haemophilia: clinical aspects. Haemophilia 2004; 10 (Suppl. 4): 140-5.

16 Leissinger CA. Use of prothrombin complex concentrates and activated prothrombin complex concentrates as prophylactic therapy in haemophilia patients with inhibitors. Haemophilia 1999; 5 (Suppl. 3): 25-32.

17 Brackmann HH, Gormsen J. Massive factor-VIII infusion in haemophiliac with factor-VIII inhibitor, high responder. Lancet 1977; 2: 933.

18 Hay CRM. Inhibitors to factor VIII/IX: treatment of inhibitors - immune tolerance induction. In: Lee CA, Berntorp EE, Hoots WK, eds. Textbook of Hemophilia. Malden, MA: Blackwell Publishing Ltd:2005; 74-9.

19 DiMichele D. Immune tolerance: critical issues of factor dose, purity and treatment complications. Haemophilia 2006; 12: 81-6.

20 Mariani G, Kroner B. International immune tolerance registry, 1997 update. Vox Sang 1999; 77 (Suppl. 1): 25-7.

21 Lenk H. The German Registry of immune tolerance treatment in hemophilia - 1999 update. Haematologica 2000; 85: 45-7.

22 DiMichele DM, Kroner BL. The North American Immune Tolerance Registry: practices, outcomes, outcome predictors. Thromb Haemost 2002; 87: $52-7$.

23 DiMichele DM, Hay CR. The international immune tolerance study: a multicenter prospective randomized trial in progress. J Thromb Haemost 2006; 4: 2271-3.

24 Agency for Health Care Policy and Research. Guidelines on the Use of Colony-stimulating Factors in Haematological Malignancies. Rockville, MD: US Department of Health and Human Services. Agency for Health Care Policy and Research; 1993. AHCPR publication 92-0023.

25 Bray GL, Gomperts ED, Courter S et al. A multicenter study of recombinant factor VIII (Recombinate): safety, efficacy, and inhibitor risk in previously 
untreated patients with hemophilia A. The Recombinate Study Group. Blood 1994; 83: 2428-35.

26 DiMichele D. Inhibitors: resolving diagnostic and therapeutic dilemmas. Haemophilia 2002; 8: 280-7.

27 Schwaab R, Brackmann HH, Meyer C et al. Haemophilia A: mutation type determines risk of inhibitor formation. Thromb Haemost 1995; 74: 1402-6.

28 Astermark J, Oldenburg J, Carlson J et al. Polymorphisms in the TNFA gene and the risk of inhibitor development in patients with hemophilia A. Blood 2006; 108: 3739-45.

29 Astermark J, Oldenburg J, Pavlova A, Berntorp E, Lefvert AK. Polymorphisms in the IL10 but not in the IL1beta and IL4 genes are associated with inhibitor development in patients with hemophilia A. Blood 2006; 107: 3167-72.

30 Astermark J, Wang X, Oldenburg J, Berntorp E, Lefvert AK. Polymorphisms in the CTLA-4 gene and inhibitor development in patients with severe hemophilia A. J Thromb Haemost 2007; 5: 263-5.

31 Astermark J, Berntorp E, White GC, Kroner BL. The Malmo International Brother Study (MIBS): further support for genetic predisposition to inhibitor development in hemophilia patients. Haemophilia 2001; 7: 267-72.

32 Lusher J, Abildgaard C, Arkin S et al. Human recombinant DNA-derived antihemophilic factor in the treatment of previously untreated patients with hemophilia A: final report on a hallmark clinical investigation. J Thromb Haemost 2004; 2: 574-83.

33 Lee CA, Lillicrap D, Astermark J. Inhibitor development in hemophiliacs: the roles of genetic versus environmental factors. Semin Thromb Hemost 2006; 32 (Suppl. 2): 10-4.

34 Lorenzo J, Lopez A, Altisent C, Aznar J. Incidence of factor VIII inhibitors in severe haemophilia: the importance of patient age. Br J Haematol 2001; 113: 600-3.

35 Koestenberger M, Raith W, Muntean W. High titre inhibitor after continuous factor VIII administration for surgery in a young infant. Haemophilia 2000; 6: 120.

36 Astermark J. Overview of inhibitors. Semin Hematol 2006; 43: S3-S7.

37 Goudemand J, Rothschild C, Demiguel V et al. Influence of the type of factor VIII concentrate on the incidence of factor VIII inhibitors in previously untreated patients with severe hemophilia A. Blood 2006; 107: 46-51.

38 Kroner BL. Comparison of the international immune tolerance registry and the North American immune tolerance registry. Vox Sang 1999; 77 (Suppl. 1): 33-7.

39 Haya S, Lopez MF, Aznar JA, Batlle J. Immune tolerance treatment in haemophilia patients with inhibitors: the Spanish Registry. Haemophilia 2001; 7: 154-9.
40 Freiburghaus C, Berntorp E, Ekman M, Gunnarsson M, Kjellberg B, Nilsson IM. Tolerance induction using the Malmo treatment model 1982-1995. Haemophilia 1999; 5: 32-9.

41 Oldenburg J, Schwaab R, Brackmann HH. Induction of immune tolerance in haemophilia A inhibitor patients by the 'Bonn Protocol': predictive parameter for therapy duration and outcome. Vox Sang 1999; 77 (Suppl. 1): 49-54.

42 Smith MP, Spence KJ, Waters EL et al. Immune tolerance therapy for haemophilia A patients with acquired factor VIII alloantibodies: comprehensive analysis of experience at a single institution. Thromb Haemost 1999; 81: 35-8.

43 Damiano ML, Hutter JJ. Jr Immune tolerance for haemophilia patients with inhibitors: analysis of the western United States experience. The Tri-Regional Nursing Group. Haemophilia 2000; 6: 526-32.

44 Rocino A, Papa M, Salerno E, Capasso F, Miraglia E, de Biasi R. Immune tolerance induction in haemophilia A patients with high-responding inhibitors to factor VIII: experience at a single institution. Haemophilia 2001; 7: 33-8.

45 Mauser-Bunschoten EP, Roosendaal G, van den Berg HM. Low-dose immune tolerance therapy: the van creveld model. Vox Sang 1996; 70 (Suppl. 1): 66-7.

46 Nilsson IM, Berntorp E, Zettervall O. Induction of immune tolerance in patients with hemophilia and antibodies to factor VIII by combined treatment with intravenous IgG, cyclophosphamide, and factor VIII. N Engl J Med 1988; 318: 947-50.

47 Berntorp E, Nilsson IM. Immune tolerance and the immune modulation protocol. Vox Sang 1996; 70 (Suppl. 1): 36-41.

48 Chabner BA, Ryan DP, Paz-Ares L, Garcia-Carbonero R, Calabresi P. Antineoplastic agents. In: Hardman JG, Limbird, LE, Gilman AG, eds. Goodman \& Gilman's the Pharmacological Basis of Therapeutics, 10th edn. New York, NY:McGraw-Hill Medical Publishing Division, 2001: 1395.

49 Gruppo RA, Valdez LP, Stout RD. Induction of immune tolerance in patients with hemophilia A and inhibitors. Am J Pediatr Hematol Oncol 1992; 14: 827.

50 Mauser-Bunschoten EP, Rosendaal FR, Nieuwenhuis HK, Roosendaal G, Briet E, van den Berg HM. Clinical course of factor VIII inhibitors developed after exposure to a pasteurised Dutch concentrate compared to classic inhibitors in hemophilia A. Thromb Haemost 1994; 71: 703-6.

51 Brackmann HH, Oldenburg J, Schwaab R. Immune tolerance for the treatment of factor VIII inhibitors twenty years' 'Bonn protocol'. Vox Sang 1996; 70 (Suppl. 1): 30-5.

52 Mariani G, Ghirardini A, Bellocco R. Immune tolerance in hemophilia-principal results from the International Registry. Report of the factor VIII 
and IX Subcommittee. Thromb Haemost 1994; 72: 155-8.

53 DiMichele D, Kroner B. and The ISTH Factor VIII/IX Subcommitee. Analysis of the North American Immune Tolerance Registry (NAITR) 1993-1997: current practice implications. Vox Sang 1999; 77: 312.

54 DiMichele DM, Kroner BL, North American Immune Tolerance Study Group. The North American Immune Tolerance Registry: practices, outcomes, outcome predictors. Thromb Haemost 2002; 87: 52-7.

55 Mariani G, Siragusa S, Kroner BL. Immune tolerance induction in hemophilia A: a review. Semin Thromb Hemost 2003; 29: 69-76.

56 Mauser-Bunschoten EP, Nieuwenhuis HK, Roosendaal G, van den Berg HM. Low-dose immune tolerance induction in hemophilia $A$ patients with inhibitors. Blood 1995; 86: 983-8.

57 Astermark J, Morado M, Rocino A et al. Current European practice in immune tolerance induction therapy in patients with haemophilia and inhibitors. Haemophilia 2006; 12: 363-71.

58 Hay CR, Brown S, Collins PW, Keeling DM, Liesner $\mathrm{R}$. The diagnosis and management of factor VIII and IX inhibitors: a guideline from the United Kingdom Haemophilia Centre Doctors Organisation. $\mathrm{Br} J$ Haematol 2006; 133: 591-605.

59 Rocino A, Salerno E, Capasso F et al. Secondary prophylaxis in severe haemophilia A: results in preventing further joint damage [abstract]. Thromb Haemost 1999; 82: 610. Abstract 1923A.

60 Unuvar A, Warrier I, Lusher JM. Immune tolerance induction in the treatment of paediatric haemophilia A patients with factor VIII inhibitors. Haemophilia 2000; 6: 150-7.

61 Barnes C, Rivard GE, Poon MC et al. Canadian multi-institutional survey of immune tolerance therapy (ITT) - experience with the use of recombinant factor VIII for ITT. Haemophilia 2006; 12: 1-6.

62 Rocino A, Santagostino E, Mancuso ME, Mannucci PM. Immune tolerance induction with recombinant factor VIII in hemophilia A patients with high responding inhibitors. Haematologica 2006; 91: 558-61.

63 Kreuz W. Epidemiology of inhibitors and current treatment strategies. Haematologica 2003; 88: EREP04.

64 Kreuz W, Escuriola-Ettingshausen C, Auerswald G. Immune tolerance induction in haemophilia $A$ patients with inhibitors: the choice of concentrate affecting success. Haematologica 2001; 86 (Suppl. 4): 16-20.

65 Auerswald G, Spranger T, Brackmann HH. The role of plasma-derived factor VIII/von Willebrand factor concentrates in the treatment of hemophilia A patients. Haematologica 2003; 88: EREP05.

66 Orsini F, Rothschild C, Beurrier P, Faradji A, Goudemand J, Polack B. Immune tolerance induction with highly purified plasma-derived factor VIII con- taining von Willebrand factor in hemophilia A patients with high-responding inhibitors. Haematologica 2005; 90: 1288-90.

67 Gringeri A, Musso R, Bernasconi S. Immunotolerance induction (ITI) with high purity FVIII/VWF concentrates in inhibitor patients with a high risk of a poor response to ITI: a prospective surveillance. J Thromb Haemost 2005; 3(Suppl. 1): A207.

68 Mannucci PM, Chediak J, Hanna W et al. and The Alphanate Study Group Treatment of von Willebrand disease with a high-purity factor VIII/von Willebrand factor concentrate: a prospective, multicenter study. Blood 2002; 99: 450-6.

69 Federici AB. The factor VIII/von Willebrand factor complex: basic and clinicalk issues. Haematologica 2003; 88 (Suppl. 9): EREP02.

70 Behrmann M, Pasi J, Saint-Remy JM, Kotitschke R, Kloft M. Von Willebrand factor modulates factor VIII immunogenicity: comparative study of different factor VIII concentrates in a haemophilia A mouse model. Thromb Haemost 2002; 88: 221-9.

71 Kasper C. Diagnosis and Management of Inbibitors to Factors VIII and IX. An Introductory Discussion for Physicians. Treatment of Hemophilia: World Federation of Hemophilia, 2004.

72 Berntorp E. Immune tolerance induction: recombinant vs. human-derived product. Haemophilia 2001; 7: 109-13.

73 Ettingshausen CE, Kreuz W. Role of von Willebrand factor in immune tolerance induction. Blood Coagul Fibrinolysis 2005; 16 (Suppl. 1): S27-31.

74 Suzuki T, Arai M, Amano K, Kagawa K and Fukutake K. Factor VIII inhibitor antibodies with C2 domain specificity are less inhibitory to factor VIII complexed with von Willebrand factor. Thromb Haemost 1996; 76: 749-54.

75 Gensana M, Altisent C, Aznar JA et al. Influence of von Willebrand factor on the reactivity of human factor VIII inhibitors with factor VIII. Haemophilia 2001; 7: 369-74.

76 Kallas A, Talpsep T. von Willebrand factor in factor VIII concentrates protects against neutralization by factor VIII antibodies of haemophilia A patients. Haemophilia 2001; 7: 375-80.

77 Berntorp E. Variation in factor VIII inhibitor reactivity with different commercial factor VIII preparations: is it of clinical importance? Haematologica 2003; 88: EREP03.

78 Freedman J, Rand ML, Russell O et al. Immunoadsorption may provide a cost-effective approach to management of patients with inhibitors to FVIII. Transfusion 2003; 43: 1508-13.

79 Knobl P, Derfler K. Extracorporeal immunoadsorption for the treatment of haemophilic patients with inhibitors to factor VIII or IX. Vox Sang 1999; 77 (Suppl. 1): 57-64.

80 Rivard GE, St Louis J, Lacroix S, Champagne M and Rock G. Immunoadsorption for coagulation factor 
inhibitors: a retrospective critical appraisal of 10 consecutive cases from a single institution. Haemophilia 2003; 9: 711-6.

81 Manco-Johnson MJ, Abshire T, Brown D et al. Initial results of a randomized prospective trial of prophylaxis to prevent joint disease in young children with factor VIII(FVIII) deficiency [abstract]. Blood 2005; 106: Abstract 3.

82 Shapiro AD, Donfield SM, Lynn HS et al. Defining the impact of hemophilia: the Academic Achievement in Children with Hemophilia Study. Pediatrics 2001; 108: E105.

83 Panicker J, Warrier I, Thomas R, Lusher JM. The overall effectiveness of prophylaxis in severe haemophilia. Haemophilia 2003; 9: 272-8.

84 Lusher JM. Inhibitor antibodies to factor VIII and factor IX: management. Semin Thromb Hemost 2000; 26: 179-88.

85 Kreuz W, Escuriola-Ettingshausen C, Mentzer D et al. Factor VIII inhibitor bypass activity (FEIBA) for prophylaxis during immune tolerance induction (ITI) in patients with high-responding inhibitors [abstract]. Blood 2000; 96: 266a. Abstract 1141.

86 Valentino L. FEIBA prophylaxis in hemophilia A patients with inhibitors results in a $95 \%$ reduction in bleeding episodes. Bangkok, Thailand: Abstract presented at: 26th World Federation of Hematology Congress; October 17-21, 2004, 2004.

87 Lindley CM, Sawyer WT, Macik BG et al. Pharmacokinetics and pharmacodynamics of recombinant factor VIIa. Clin Pharmacol Ther 1994; 55: 638-48.

88 Villar A, Aronis S, Morfini M et al. Pharmacokinetics of activated recombinant coagulation factor VII (NovoSeven) in children vs. adults with haemophilia A. Haemophilia 2004; 10: 352-9.

89 Varadi K, Negrier C, Berntorp E et al. Monitoring the bioavailability of FEIBA with a thrombin generation assay. J Thromb Haemost 2003; 1: 2374-80.

90 Konkle BA, Ebbesen LS, Friedrich U et al. Secondary Prophylactic Treatment with rFVIIa in Patients with Haemophilia $A$ or $B$ and Inhibitors with High Requirements for On-demand Treatment: Analysis of Primary Endpoint and Safety. Vancouver, Canada: Poster presented at: XXVII International Congress of the World Federation of Hemophilia; 21-5 May 2006.

91 Saxon BR, Shanks D, Jory CB, Williams V. Effective prophylaxis with daily recombinant factor VIIa (rFVIIa-Novoseven) in a child with high titre inhibitors and a target joint. Thromb Haemost 2001; 86: 1126-7.

92 Ehrlich HJ, Henzl MJ, Gomperts ED. Safety of factor VIII inhibitor bypass activity (FEIBA): 10-year compilation of thrombotic adverse events. Haemophilia 2002; 8: 83-90.

93 Kreuz W, Escuriola-Ettingshausen C, Martinez I, Mentzer D, Figura S, Klarmann D. Efficacy and safety of factor VIII inhibitor bypass activity (FEIBA) for longterm prophylaxis in patients with high-responding inhibitors [abstract]. Blood 2000; 96: 265a. Abstract 1140.

94 Hilgartner MW, Makipernaa A, DiMichele DM. Long-term FEIBA prophylaxis does not prevent progression of existing joint disease. Haemophilia 2003; 9: 261-8.

95 Antunes SV, Vicari P, Cavalheiro S, Bordin JO. Intracranial haemorrhage among a population of haemophilic patients in Brazil. Haemophilia 2003; 9: 573-7.

96 Carcao MD, Connolly BL, Chait P et al. Central venous catheter-related thrombosis presenting as superior vena cava syndrome in a haemophilic patient with inhibitors. Haemophilia 2003; 9: 578-83.

97 Ewenstein BM, Valentino LA, Journeycake JM et al. Consensus recommendations for use of central venous access devices in haemophilia. Haemophilia 2004; 10: 629-48.

98 Valentino LA, Ewenstein B, Navickis RJ, Wilkes MM. Central venous access devices in haemophilia. Haemophilia 2004; 10: 134-46.

99 Tarantino MD, Lail A, Donfield SM et al. Surveillance of infectious complications associated with central venous access devices in children with haemophilia. Haemophilia 2003; 9: 588-92.

100 Warrier I, Baird-Cox K, Lusher JM. Use of central venous catheters in children with haemophilia: one haemophilia treatment center experience. Haemophilia 1997; 3: 194-8.

101 Bollard CM, Teague LR, Berry EW, Ockelford PA. The use of central venous catheters (portacaths) in children with haemophilia. Haemophilia 2000; 6: 66-70.

102 Domm JA, Hudson MG, Janco RL. Complications of central venous access devices in paediatric haemophilia patients. Haemophilia 2003; 9: 50-6.

103 van Dijk K, van Der Bom JG, Bax KN, Van Der Zee DC and Van Den Berg MH. Use of implantable venous access devices in children with severe hemophilia: benefits and burden. Haematologica 2004; 89: 18994.

104 van den Berg HM, Fischer K, Roosendaal G, MauserBunschoten EP. The use of the Port-A-Cath in children with haemophilia - a review. Haemophilia 1998; 4: 418-20.

105 Hay CRM, Keegan J, Goldstone J et al. International Immune Tolerance (ITI) Study: Frequency of Central Venous Line Infection and Effect on ITI Outcome. Poster presented at: 27th World Federation of Hematology Congress; 21-25 May 2006; Vancouver, Canada. 2006.

106 Journeycake JM, Quinn CT, Miller KL, Zajac JL, Buchanan GR. Catheter-related deep venous thrombosis in children with hemophilia. Blood 2001; 98: 1727-31.

107 Santagostino E, Gringeri A, Berardinelli L, Beretta C, Muca-Perja M, Mannucci PM. Long-term safety and 
feasibility of arteriovenous fistulae as vascular accesses in children with haemophilia: a prospective study. Br J Haematol 2003; 123: 502-6.

108 National Institute of Diabetes and Digestive and Kidney Diseases. Vascular Access for Hemodialysis. NIH Publication no. 05-4554. January 2005. Available at: http://www.kidney.niddk.nih.gov/kudiseases/ pubs/pdf/vascularaccess.pdf. (accessed on 17 January 2007).

109 Carcao M, St Louis J, Poon MC et al. Rituximab for congenital haemophiliacs with inhibitors: a Canadian experience. Haemophilia 2006; 12: 7-18.

110 Collins PW. Novel therapies for immune tolerance in haemophilia A. Haemophilia 2006; 12 (Suppl. 6): 94-101.

111 Wiestner A, Cho HJ, Asch AS et al. Rituximab in the treatment of acquired factor VIII inhibitors. Blood 2002; 100: 3426-8.

112 Stasi R, Brunetti M, Stipa E, Amadori S. Selective B-cell depletion with rituximab for the treatment of patients with acquired hemophilia. Blood 2004; 103 : 4424-8.

113 Dunkley S, Lindeman R. Successful treatment of a high titre factor VIII inhibitor with rituximab alone [abstract]. J Thromb Haemost 2005; 3 (Suppl. 1): Abstract P631.

114 Escobar M, Kempton C and Ma A. Successful treatment of an autoantibody in congenital hemophilia with rituximab [abstract]. Blood 2002; 100: 109b abstract 3915.

115 Curry N, Stanworth S, Keeling D. The use of rituximab in two children with allo-antibodies towards factor VIII. Br J Haematol 2006; 133: 214-6.

116 Curtin J, Misra A, Teo J, Webster B, Lammi A. Use of rituximab as an alternative strategy for the management of difficult high titre inhibitors in children with hemophilia A [abstract]. Haemophilia 2004; 10 (Suppl. 3): 57. Abstract 30.

117 Linde R, Escuriola-Ettinghausen C, Konigs C, Dunsch D, Stoll H. Kreuz W. Rituximab as a new inhibitor elimination agent in high-titer inhibitor patients - a long-term follow-up [abstract]. Haemophilia 2004; 10 (Suppl. 3): 60. Abstract 51.

118 Mateo J, Badell I, Forner R, Borrell M, Tizzano E, Fontcuberta J. Successful suppression using Rituximab of a factor VIII inhibitor in a boy with severe congenital haemophilia: an example of a significant decrease of treatment costs. Thromb Haemost 2006; 95: 386-7.

119 Mathias M, Khair K, Hann I, Liesner R. Rituximab in the treatment of alloimmune factor VIII and IX antibodies in two children with severe haemophilia. Br J Haematol 2004; 125: 366-8.

120 Medeiros BC, Geraghty S, Stabler SP. Improved response to immune tolerance therapy for factor VIII inhibitor after rituximab therapy [abstract]. Blood 2002; 100: 103b. Abstract 3890.
121 Moschovi M, Aronis S, Trimis G, Platokouki H, Salavoura K. Tzortzatou-Stathopoulou F. Rituximab in the treatment of high responding inhibitors in severe haemophilia A. Haemophilia 2006; 12: 95-9.

122 Pruthi RK, Schmidt KA, Slaby JA, Hook CC, Nichols WL. Rituximab treatment of FVIII inhibitors in congenital hemophilia A (cHA) [abstract]. J Thromb Haemost 2005; 3 (Suppl. 1): Abstract P652.

123 Fox RA, Neufeld EJ, Bennett CM. Rituximab for adolescents with haemophilia and high titre inhibitors. Haemophilia 2006; 12: 218-22.

124 IITI. International, Randomised, Controlled Trial of Immune-tolerance Induction. Available at: http:// www.itistudy.com (accessed on 12 January 2007).

125 Teitel J. Inhibitor economics. Semin Hematol 2006; 43: S14-S17.

126 Mariani G, Kroner B. Immune tolerance in hemophilia and inhibitors: a cost analysis. Transfusion 2000; 40: 495-6.

127 Colowick AB, Bohn RL, Avorn J, Ewenstein BM. Immune tolerance induction in hemophilia patients with inhibitors: costly can be cheaper. Blood 2000; 96: 1698-702.

128 Gringeri A, Mantovani LG, Scalone L, Mannucci PM. Cost of care and quality of life for patients with hemophilia complicated by inhibitors: the COCIS Study Group. Blood 2003; 102: 2358-63.

129 Gringeri A, Mantovani L, Mackensen SV. Quality of life assessment in clinical practice in haemophilia treatment. Haemophilia 2006; 12 (Suppl. 3): 22-9.

130 Wasserman J, Aday LA, Begley CE, Ahn C, Lairson DR. Measuring health state preferences for hemophilia: development of a disease-specific utility instrument. Haemophilia 2005; 11: 49-57.

131 Scalone L, Mantovani LG, Mannucci PM, Gringeri A. Quality of life is associated to the orthopaedic status in haemophilic patients with inhibitors. Haemophilia 2006; 12: 154-62.

132 Kreuz W, Ehrenforth S, Funk M et al. Immune tolerance therapy in paediatric haemophiliacs with factor VIII inhibitors: 14 years follow-up. Haemophilia 1995; 1: 24-32.

133 Hay CR. Factor VIII inhibitors in mild and moderateseverity haemophilia A. Haemophilia 1998; 4: 558-63.

134 Hay CR, Ludlam CA, Colvin BT et al. Factor VIII inhibitors in mild and moderate-severity haemophilia A. UK Haemophilia Centre Directors Organisation. Thromb Haemost 1998; 79: 762-6.

135 d'Oiron R, Volot F, Reynaud J et al. Impact of choice of treatment for bleeding episodes on inhibitor outcome in patients with mild/moderate hemophilia A and inhibitors. Semin Hematol 2006; 43: S3-S9.

136 DiMichele DM. Management of factor VIII inhibitors. Int J Hematol 2006; 83: 119-25.

137 Key NS. Inhibitors in congenital coagulation disorders. Br J Haematol 2004; 127: 379-91. 
138 Warrier I, Lusher JM. Development of anaphylactic shock in haemophilia B patients with inhibitors. Blood Coagul Fibrinolysis 1998; 9 (Suppl. 1): S125-8.

139 Warrier I, Ewenstein BM, Koerper MA et al. Factor IX inhibitors and anaphylaxis in hemophilia B. J Pediatr Hematol Oncol 1997; 19: 23-7.

140 Thorland EC, Drost JB, Lusher JM et al. Anaphylactic response to factor IX replacement therapy in haemophilia B patients: complete gene deletions confer the highest risk. Haemophilia 1999; 5: 101-5.

141 Ketterling RP, Vielhaber EL, Lind TJ, Thorland EC, Sommer SS. The rates and patterns of deletions in the human factor IX gene. Am J Hum Genet 1994; 54: 201-13.

142 Ewenstein BM, Takemoto C, Warrier I et al. Nephrotic syndrome as a complication of immune tolerance in hemophilia B. Blood 1997; 89: 1115-6.

143 DiMichele DM. Immune tolerance: critical issues of factor dose, purity and treatment complications. Haemophilia 2006; 12 (Suppl. 6): 81-86.

144 Wermes C, von Depka Prondzinski M, Welte K, Sykora K.-W. New strategy for the treatment of fac- tor IX inhibitors in severe haemophilia B [abstract]. Blood 2000; 96: 267A. Abstract 1148.

145 Ananyeva NM, Lacroix-Desmazes S, Hauser CA et al. Inhibitors in hemophilia A: mechanisms of inhibition, management and perspectives. Blood Coagul Fibrinolysis 2004; 15: 109-24.

146 Reding MT. Immunological aspects of inhibitor development. Haemophilia 2006; 12 (Suppl. 6): 30-6.

147 Tarantino M, Ma A, Aledort L. Safety of human plasma-derived clotting factor products and their role in hemostasis in patients with hemophilia: meeting report. Haemophilia (in press).

148 Dasgupta S, Repesse Y, Bayry J et al. VWF protects FVIII from endocytosis by dendritic cells and subsequent presentation to immune effectors. Blood 2007; 109: 610-2.

149 Barnes C, Brewin T, Ekert H. Induction of immune tolerance and suppression of anaphylaxis in a child with haemophilia B by simple plasmapheresis and antigen exposure: progress report. Haemophilia 2001; 7: 439-40. 